NBER WORKING PAPER SERIES

\title{
DEVELOPMENT, DISCOURAGEMENT, OR DIVERSION? NEW EVIDENCE ON THE EFFECTS OF COLLEGE REMEDIATION
}

\author{
Judith Scott-Clayton \\ Olga Rodriguez \\ Working Paper 18328 \\ http://www.nber.org/papers/w18328
NATIONAL BUREAU OF ECONOMIC RESEARCH
1050 Massachusetts Avenue
Cambridge, MA 02138

August 2012

This work was funded by the Bill \& Melinda Gates Foundation. The authors would like to thank administrators of the community college system analyzed here for providing access to these data; we also thank Thomas Bailey, Shanna Jaggars, Michelle Hodara, Maria Encina Morales and other members of the Community College Research Center for helpful comments and suggestions. The views expressed herein are those of the authors and do not necessarily reflect the views of the National Bureau of Economic Research.

NBER working papers are circulated for discussion and comment purposes. They have not been peerreviewed or been subject to the review by the NBER Board of Directors that accompanies official NBER publications.

(C) 2012 by Judith Scott-Clayton and Olga Rodriguez. All rights reserved. Short sections of text, not to exceed two paragraphs, may be quoted without explicit permission provided that full credit, including (c) notice, is given to the source. 
Development, Discouragement, or Diversion? New Evidence on the Effects of College Remediation Judith Scott-Clayton and Olga Rodriguez

NBER Working Paper No. 18328

August 2012

JEL No. I21,I23

\begin{abstract}
$\underline{\text { ABSTRACT }}$
Half of all college students take at least one remedial course as part of their postsecondary experience, despite mixed evidence on the effectiveness of this intervention. Using a regression-discontinuity design with data from a large urban community college system, we extend the research on remediation in three ways. First, we articulate three alternative models of remediation to help guide interpretation of sometimes conflicting results in the literature. Second, in addition to credits and degree completion we examine several under-explored outcomes, including the initial decision to enroll, grades in subsequent college courses, and post-treatment proficiency test scores. Finally, we exploit rich high school background data to examine heterogeneity in the impact of remedial assignment by predicted academic risk. We find that remediation does little to develop students' skills. But we also find relatively little evidence that it discourages either initial enrollment or persistence, except for a subgroup we identify as potentially mis-assigned to remediation. Instead, the primary effect of remediation appears to be diversionary: students simply take remedial courses instead of college-level courses. These diversionary effects are largest for the lowest-risk students. Implications for remediation policy are discussed.
\end{abstract}

\author{
Judith Scott-Clayton \\ Teachers College \\ Columbia University \\ 525 W.120th Street, Box 174 \\ New York, NY 10027 \\ and NBER \\ scott-clayton@tc.columbia.edu \\ Olga Rodriguez \\ Teachers College \\ Columbia University \\ 525 W.120th Street, Box 174 \\ New York, NY 10027 \\ or2125@columbia.edu
}




\section{INTRODUCTION}

Remedial education, or "developmental" education as it is called in the field, may be the most widespread and costly intervention aimed at addressing a perceived lack of preparation among incoming college students. ${ }^{1}$ Remedial courses, which do not count towards degree completion, are intended to help students master the skills needed for successful progression toward their degree goals. Half of all undergraduates will take one or more remedial courses while enrolled. ${ }^{2}$ At community colleges, remedial credits represent approximately 10 percent of all credits earned, suggesting that the cost of remediation may be nearly $\$ 4$ billion dollars per year in this sector alone. ${ }^{3}$

Previous research, primarily relying on regression-discontinuity (RD) analyses comparing students just above and below remedial test score cutoffs, has found mixed evidence at best regarding whether assignment to remediation actually improves student outcomes (Bettinger \& Long, 2005, 2009; Boatman \& Long, 2011, Calcagno \& Long, 2008; Dadgar, 2012; Hodara, 2012; Martorell \& McFarlin, 2011). But remediation is not going away, and if anything remediation policies trend towards becoming stricter over time (Hughes \& Scott-Clayton, 2011).

The growing body of research evidence may have had limited policy impact for two reasons: first, lingering uncertainty about the generalizability of prior findings to other contexts, particularly to lower-ability students who may not be represented in local RD estimates; second, the reality that remediation may serve other purposes beyond simply developing students'

\footnotetext{
${ }^{1}$ We use the terms "remedial" and "developmental" interchangeably throughout the paper.

${ }^{2}$ Estimate based on BPS:2009 transcript data (National Center for Education Statistics, 2012).

${ }^{3}$ Credit attainment estimates based on BPS:2009 transcript data (National Center for Education Statistics, 2012) which indicate an average of 2 remedial courses (roughly 6 "equated" credits) and 60 total credits earned within 6 years among first-time beginning students entering public two-year colleges. The Delta Cost Project (2012) estimates total expenditures of roughly $\$ 12,957$ per FTE per year, implying a per-credit cost of roughly \$540 (since full-time is defined as 24 credits per year). This in turn implies the cost of remediation is roughly $\$ 3,200$ per community college entrant (not per remediated student). With over 1.2 million first-time students entering community colleges annually, this suggests national costs of nearly $\$ 4$ billion annually.
} 
college readiness. For example, an unadvertised but implicit function of remedial assignment may be to signal students about their likelihood of college completion; it may be efficient to both the student and the institution to realize this and adjust their investments sooner rather than later. Moreover, regardless of its effectiveness in remediating skill deficiencies, remediation may still serve as an expedient form of student tracking. Even if remediated students never make it to college-level coursework, students in both remedial and college-level courses may learn more during their three semesters of attendance (the average, in our sample) than if they were all grouped in already-crowded college courses.

Our study makes three primary contributions. First, we articulate three alternative models of remediation: as development for future coursework, discouragement from further study, or simply a diversion onto a separate track. Second, using rich administrative data on 100,000 students in a Large, Urban Community College System (LUCCS), we utilize a regression discontinuity approach (comparing students just above and below remedial test score cutoffs) to examine several outcomes underexplored in the prior literature, including the initial decision to enroll, grades in subsequent college courses in the same subject, and post-treatment scores on a proficiency exam required in order to earn any degree. ${ }^{4}$ Finally, we explore impact heterogeneity using a novel new approach that gets us beyond the usual local nature of RD estimates: because the placement test scores used for the RD are quite noisy, we use rich high school background data to identify students with varied levels of prior academic risk who all scored around the placement test cutoff.

Our findings affirm prior research indicating that assignment to remediation does not develop students' skills sufficiently to increase their rates of college success (Calcagno \& Long, 2008; Martorell \& McFarlin, 2011). On the other hand, neither does remedial assignment appear

\footnotetext{
${ }^{4}$ The system requested anonymity as a condition of providing access to the data.
} 
to be a significant discouragement to student progress, except for one group we identify as potentially mis-assigned to remediation: students who passed a more difficult writing test, but just barely failed a significantly easier reading test. Among other negative effects, this group experienced an 8 percentage point increase in the likelihood of dropping out.

Overall, the primary effect of remediation appears to be diversionary: students generally enroll and persist at the same rates but simply take remedial courses instead of college-level courses. While our model suggests diversion is not necessarily a bad thing, our findings provide some reason for concern. First, we find that potentially one-quarter of students diverted from college-level courses in math, and up to 70 percent of those diverted in reading, would have earned a B or better in the relevant college course. Further, our analysis of impacts by prior predicted dropout risk suggests that diversionary effects are largest for the lowest-risk students, and we fail to find positive effects for any risk subgroup.

The remainder of the text proceeds as follows: in Section II, we describe our conceptual framework and review the prior literature. In Section III, we describe our empirical strategy. In Section IV we present our main results and specification checks. Section V explores heterogeneous effects by test type and prior predicted dropout risk. Section VI concludes.

\section{CONCEPTUAL FRAMEWORK AND PRIOR LITERATURE}

The increasing availability of large-scale administrative datasets makes it increasingly feasible for researchers to examine dozens of outcomes for any given intervention. Carefully delineating a program's potential mechanisms is thus essential to identifying the key outcomes of interest and interpreting the resulting pattern of estimates. Prior research describes several purposes that remedial coursework might serve within an institution. We categorize these 
potential functions into three broad models: remediation as skill development that prepares students for future college-level courses, as a discouragement that stigmatizes students and sends a signal about their probability of college success, and finally as a diversion that steers students out of college-level courses and reduces heterogeneity within classrooms. These functions may or may not be intentional, and are not mutually exclusive. Below, we describe each model and summarize the relevant causal research in context.

\section{A. The Development Model}

Prior research has documented low levels of preparation among recent cohorts of high school graduates (Greene \& Forster, 2003). At open-access institutions, remedial coursework is intended to develop underprepared students' skills so that they have the opportunity to pursue college success regardless of prior preparation (RP Group, 2007). Indeed, this central function is expressed in terminology: many institutions and researchers now eschew the traditional term "remedial education" in favor of the more optimistic "developmental education." In this view, developmental education is an investment: compared to how they might have fared without remediation, these students may experience an initial negative setback as they delay some college coursework but should reap benefits over the longer term. These longer term benefits should most directly include improved performance in college-level courses, which may in turn lead to greater persistence and higher rates of degree completion and/or transfer.

Three prior evaluations of remedial education provide evidence on the developmental model by examining whether remediated students eventually complete more college-level credits, persist for longer, and/or complete degrees or transfer at higher rates than similar students who took the most direct path. The first quasi-experimental study of remediation, by Bettinger \& Long (2009), provides the most encouraging evidence in support of the 
developmental model. They take advantage of seemingly arbitrary variation in placement test cutoff policies across two- and four-year campuses in Ohio, using distance to college as an instrument for students' probability of remediation. They find some important positive impacts: students who were more likely to be remediated (by virtue of the cutoff policy at the nearest school) were more likely to complete a bachelor's degree in four years. They also find that those remediated in English were less likely to drop out in their first year. On the other hand, mixed with these positive effects they also find some significant negative impacts. For example, remediated students in both English and math completed significantly fewer total credits, while those remediated in math were more likely to drop out in their first year.

Two subsequent studies using a regression-discontinuity (RD) approach, comparing students just above and below test score cutoffs for remediation within institutions, find little evidence to support the development model. A study using data from over 100,000 two-year entrants in the state of Florida found no impact on retention, degree completion, transfer, or completion of college credits for students near the cutoff (Calcagno \& Long, 2008). Martorell and McFarlin (2011), who studied over 250,000 students in Texas public two- and four-year colleges, find that assignment to remediation decreased the probability of completing additional years of college and reduced credit accumulation, with no impact on degree attainment.

It is worth noting that the prior literature has not fully explored one set of outcomes that is particularly relevant to the development model: grades in subsequent college-level coursework in the remediated subject. If remediation improves students' performance in the college-level courses that directly follow remediation, this alone might justify the intervention even without broader impacts on credits or graduation, which may be asking too much of a fairly narrow treatment. Of course, grades can be a tricky outcome to examine causally because many students 
simply never reach college-level coursework. Two prior studies examine whether remediated students have a higher likelihood of ever completing a college-level course in the relevant subject (Calcagno \& Long, 2008; Dadgar 2012). These studies find no effect, but potential impacts higher in the grade distribution are unexplored. Boatman \& Long (2010) take a different approach, examining grades only for students who attempted a college-level course; however, these comparisons do not have a causal interpretation because they are conditional on a posttreatment outcome (ever taking a college-level course). ${ }^{5}$ In order examine grades while preserving our causal identification strategy, we examine binary outcomes such as whether or not a student ever earned a B or better or $\mathrm{C}$ or better in the first college-level course in the relevant subject (where those never taking the course are entered as zeros).

\section{B. The Discouragement Model}

Martorell \& McFarlin's (2011) finding that assignment to remediation negatively impacts college persistence suggests the presence of discouragement or stigma effects. This is consistent with evidence on the impact of test score performance labels at the high school level, which indicates that being labeled as a poor performer discourages students from enrolling in college (Papay, Murnane \& Willett, 2011). In this model, an assignment to remediation may send a message to students that they are not "college material." This is in line with Burton Clark's (1960) description of a "cooling out" process in higher education, in which obstacles encountered by the student in college serve to gradually diminish their degree aspirations. Note that while discouragement is typically framed as an undesirable potential side effect, it is

\footnotetext{
${ }^{5}$ They find no effects of remediation versus those assigned directly to college level in math or reading, but find that those assigned to lower levels of writing remediation have higher grades (if they ever take a college-level course) than those assigned to higher levels of writing remediation.
} 
possible to take a more agnostic view: a remedial assignment may simply give students a signal about their preparation that causes them to rationally reevaluate the benefits of enrollment. ${ }^{6}$

Allowing for potential discouragement effects has several implications for our study.

First, it highlights the importance of tracking students from the point that they receive their first test scores, not only after they enroll. While all of the prior remediation studies look for negative impacts on persistence or completion conditional on enrollment, ours joins just one other recent study in examining whether there are any effects on college enrollment between the time of the first test and initial course registration. Martorell, McFarlin, \& Xue (2011), using the same Texas data as in their prior study, find no significant effect on initial enrollment in either direction.

Given the variation in remedial testing and assignment procedures across systems, our study will help establish whether this finding generalizes to a different context.

Second, the discouragement model suggests that some students assigned to remediation may be negatively affected even if they never actually enroll in remediation. With the exception of Martorell, McFarlin \& Xue (2011), the prior research typically uses remedial assignment policy as an instrumental variable (IV) for actual remedial course-taking (Bettinger \& Long 2009; Calcagno \& Long 2008; Martorell \& McFarlin 2011). But unless one is willing to assume away any direct effects of the remedial label, only the reduced-form effect of remedial assignment can be credibly established. We thus focus primarily on reduced-form effects of remedial assignment.

Finally, the discouragement model highlights the importance of considering heterogeneous effects when evaluating remedial policies: some students may be discouraged, while other students may do better than they would otherwise. One potential limitation of any

\footnotetext{
${ }^{6}$ This is also in line with Manski's (1989) model of college education as experimentation, in which the dropout decision is the result of new information regarding skills and preferences.
} 
RD study is that the estimated effects are local to students scoring near remedial cutoffs (that is, the highest-ability remediated students). Defenders of the developmental model may legitimately argue that higher-ability students might be the most sensitive to discouragement effect and least likely to benefit from developmental instruction, implying that lower-ability students might experience more positive effects. Martorell \& McFarlin (2011) are able to examine RD effects separately for cohorts with higher and lower cutoffs and find less negative (but not positive) effects when the marginal student is of lower measured ability.

Recent RD studies have also explored the effects of assignment to lower levels of remediation (Boatman \& Long, 2010; Hodara, 2012; Dadgar, 2012). These studies compare students just above and below test score cutoffs for longer versus shorter (or more versus less intensive) remedial sequences, rather than comparing those above and below the threshold for college-level coursework. These studies have also found less negative effects, with a smattering of some positive effects of assignment to lower remedial levels. This pattern is consistent either with less negative effects for lower-ability students, or simply reflects a different bundle of treatment (for example, it may be that discouragement effects apply equally to remediated students regardless of level, but those at lower levels get a larger "dose" of the developmental mechanism).

Our study provides a new means of exploring heterogeneous effects in RD designs: although the placement test scores used for assignment are often assumed to be a measure of ability, they are in fact quite noisy and error-prone (ACT, Inc. 2006; Scott-Clayton, 2012). This implies that even around the cutoff there is variation in student ability. We use rich demographic and background data on high school achievement to predict students' pre-treatment risk of 
dropping out of college. We then run our RD analysis separately for subgroups based on this index of academic risk.

\section{The Diversion Model}

A third possible view of remediation is neither as optimistic as the development model nor as pessimistic as the discouragement model. Under the diversion model, the primary role of remediation is simply to separate students of different ability onto different course tracks. The goal in this case need not be to prepare remediated students for future coursework, but simply to maximize learning gains for both remediated and non-remediated students for as long as they remain enrolled (which, in our sample, is an average of three semesters). While research on K-12 education largely finds that low-achieving students learn more when they are placed in heterogeneous classrooms (Burris, Heubert, and Levin, 2006; Peterson, 1989; White, Gamoran, Porter, Smithson, 1996), some studies have found that tracking may be beneficial, or at least not harmful, to students of lower ability (Figlio \& Page, 2002; Zimmer, 2003).

Moreover, there is strong evidence of peer effects in higher education (Sacerdote, 2001; Zimmerman, 2003; Winston \& Zimmerman, 2003; Carrell, Fullerton \& West, 2009), raising the concern that allowing too many underprepared students into college-level courses might depress the achievement of the better-prepared. While Carrell, Fullerton \& West (2009) find that positive peer effects for low-achieving students outweigh negative effects for high-achieving students, it is not obvious that their results (in the context of the U.S. Air Force Academy) would extrapolate to community college students. Finally, if college-level courses are already at capacity, then allowing too many students into college-level coursework might depress achievement because of overcrowding, regardless of whether or not the ability mix shifts. 
The prior causal research on remediation has not been designed to examine impacts on non-remediated students, and our study is no different on this dimension. Like prior research, we are able to examine diversion by looking at the relative impact on total credits (including both remedial and college-level courses) versus college-level credits; a diversion story suggests there may be no effect on the former but negative effects on the latter. Both Calcagno \& Long (2008) and Martorell \& McFarlin (2011) find evidence of diversion effects. However, a potential outcome under the diversion model is that even if remediated students never make it to college level coursework, they may learn more in their remedial courses than they would have otherwise. This suggests that one should examine some direct measures of learning beyond simply credits and credentials. Martorell \& McFarlin (2011) find no impact on labor market outcomes, though their estimates are too noisy to rule out modest effects in either direction. We extend the literature on this front by examining post-assignment scores on a proficiency exam that is required of all students in order to graduate.

\section{EMPIRICAL STRATEGY}

\section{A. Institutional context}

Our analysis focuses on first-time degree-seeking students who were admitted to one of six community colleges in a single large, urban community college system (LUCCS) between Fall 2001 and Fall 2007. Over the period under study in this report, LUCCS utilized two different exams for placement in math. From 2001 to 2004 LUCCS utilized a single-score math exam that was developed in-house; since 2004 LUCCS has utilized scores from the COMPASS $®$ numerical skills/pre-algebra module as well as the algebra module for remedial 
placement. ${ }^{7}$ For reading/writing placement, over the entire period LUCCS used the COMPASS $®$ reading exams as well as a writing exam that LUCCS adapted slightly from the standard COMPASS $®$ writing module (and which LUCCS grades in-house).

As in many systems, students are exempted from the placement exams if they score above a certain level either on the SAT, ACT, or on a standardized state high school exam. Approximately 20 percent of entering students were exempt from placement testing in math, and approximately 25 percent were exempt in English for the cohorts under study. These exempt students are excluded from the analysis. All students who are not exempted from placement testing must take the relevant placement exam(s) prior to initial enrollment. ${ }^{8}$ The retesting policy is strict: students may not retake a placement exam until they have completed either a remedial course or at least 20 hours of documented participation in an alternative intervention, which might include a workshop or regular tutoring.

Each year, the LUCCS central office establishes minimum cut scores for access to college-level courses that apply to all of the LUCCS institutions; however, schools are free to establish higher cutoffs, and some schools in some years were allowed to have lower cutoffs on the writing exam on a pilot basis. We determined the cutoff policies that were in place at each college in each year by examining information from college course catalogs and following up with institutional administrators if necessary; we also check these stated cutoffs against the actual course-taking patterns by test score that we can observe in our data.

Students are encouraged, but not required, to begin their remedial coursework immediately upon enrollment. Although they may be able to access some college-level courses before completing remediation, many college-level courses require freshman composition in

\footnotetext{
${ }^{7}$ The COMPASS $®$ suite is a product of ACT, Inc.

${ }^{8}$ This is in contrast to Texas's system, analyzed in Martorell \& McFarlin (2011), in which students could delay their placement exam until after enrollment.
} 
particular as a prerequisite. Moreover, students must pass college-level freshman composition and at least one credit-bearing math course in order to earn any degree, so a student cannot graduate without successfully exiting remediation. Students' compliance with course placement decisions appears to be high at LUCCS institutions: while some students may not enroll in the required remedial course immediately, relatively few students who are assigned to a remedial course circumvent that placement to enroll in a college-level course.

\section{B. Data and sample}

The data for this analysis were provided under a restricted-use agreement with LUCCS. All students are followed for three years after they were first tested (we can also look at longerterm outcomes for some cohorts). We can track students' credits, grades, and degree outcomes even if they transfer to another public two- or four-year institution within the same urban area. Our data includes information on all placement exam administrations, so we are able to identify and utilize the scores from the students' first test attempt. Finally, our sample includes tested students even if they ultimately did not enroll at LUCCS, enabling us to examine whether remedial placement may impact the enrollment decision itself.

Table 1 provides descriptive information on the full sample of test-takers and main subsamples for the analysis. Column 1 shows that among all test-takers during this time period, 72 percent were assigned to developmental math, 72 percent were assigned to developmental writing, and 38 percent were assigned to developmental reading. Overall, approximately 90 percent were assigned to remediation in one or more subjects. ${ }^{9}$ This proportion has generally been flat or declining over the sample timeframe except for discrete and substantial jumps when new tests or new cutoffs were implemented.

\footnotetext{
${ }^{9}$ These rates are higher than those observed in the system overall (in which roughly 82 percent are assigned to remediation in at least one subject), because 20 to 25 percent of entrants are exempt from testing in each subject.
} 
Reflecting its urban location, LUCCS students are highly diverse, with 34 percent identifying their race/ethnicity as Hispanic, 28 percent identifying as non-Hispanic black, 14 percent identifying as non-Hispanic white, 11 percent identifying as Asian/Pacific Islander, and 7 percent identifying as another race/ethnicity. More than half are identified as speaking a primary language other than English. ${ }^{10}$

Table 1 indicates that a substantial proportion of students -17 percent overall—who take a placement test at one of the LUCCS colleges never enroll (or at least still had not enrolled three years after their first test). ${ }^{11}$ This highlights the importance of looking at initial enrollment as a margin that could be affected by remedial assignment. The average student enrolled for 3.3 semesters over three years, and nearly two-thirds (64 percent) had dropped out (not enrolled, no degree) at the end of the three year follow-up period. ${ }^{12}$ An additional 24 percent were still enrolled at one of the LUCCS colleges, and the remainder (12 percent) had either completed a degree or transferred to a local public four-year institution. Finally, Table 1 indicates that approximately 13 percent of tested students had taken and passed a college proficiency exam (CPE) required for graduation; those who took the exam scored an average of 42 points (out of 72 possible; a 34 is required to pass).

\section{Identification strategy}

Table 1 provides mean outcome levels for those students assigned to remediation in any subject as well as means for those not assigned to any remediation (including students who were exempt from testing). While comparisons between these two groups may provide useful context, they are unlikely to have any causal interpretation; students who score lower on placement

\footnotetext{
${ }^{10}$ This measure of language minority status is derived from self-reported native language and country of origin as indicated on the college application.

${ }^{11}$ Note that for a small proportion of students who took a placement exam while still enrolled in high school, the three year follow up period does not begin until after high school graduation.

${ }^{12}$ Students who transferred to private or out-of-state institutions cannot be distinguished from dropouts in our data.
} 
exams are likely to do worse on average than those who score more highly regardless of the effect of remediation.

Following prior literature by Calcagno \& Long (2008) and Martorell \& McFarlin (2011), we utilize a regression discontinuity (RD) design to identify the causal effect of remedial assignment for those students who score near the cutoff. The intuition underlying the approach is simple: if we assume that the underlying relationship between test scores and future outcomes is continuous and that nothing other than the placement policy varies discontinuously at the cutoff, then we may attribute any observed discontinuity in outcomes at the cutoff to the placement policy. For example, while we might expect that degree completion would be positively related to test scores, there is no reason other than the placement policy to expect a discontinuous jump (or dropoff) in this relationship at the test score cutoff.

This intuition can be formalized using Rubin's (1974) potential outcomes framework, following Imbens \& Lemieux (2008). We would like to compare an individual's potential outcome if they are assigned to remediation, denoted as $\mathrm{Y}(1)$, to that individual's potential outcome if they are not assigned to remediation, denoted as $\mathrm{Y}(0)$. Assignment to remediation is determined by whether or not the test score, $\mathrm{X}$, is above or below some cutoff, c. The fundamental problem of causal inference is that we can never observe both $\mathrm{Y}(1)$ and $\mathrm{Y}(0)$ for a single individual. However, as long as the relationship between potential outcomes and test scores is continuous, then we may define a causal effect:

$$
\text { (1) } \beta_{R D}=\lim _{x \rightarrow c^{-}} E[Y \mid X=x]-\lim _{x \rightarrow c^{+}} E[Y \mid X=x]
$$

In other words, the RD estimator is simply the difference between two regression functions at the cutoff, where one function is estimated by approaching the cutoff from below and the other is estimated by approaching the cutoff from above. Even if there is a systematic relationship 
between test scores and outcomes, as long as this relationship is continuous there is no reason to expect the limits in equation (1) to differ except because of the difference in remedial assignment. The estimated RD impact is "local" to the cutoff, meaning the estimate only applies to individuals near the cutoff, unless further assumptions are made.

There are multiple ways to estimate $\beta_{R D}$ in practice. We follow Imbens \& Lemieux (2008) by focusing primarily on a local linear estimation that is limited to a narrow bandwidth around the cutoff. The generic specification takes the form:

$$
\begin{aligned}
& Y_{i}=\alpha+\beta_{1}\left(\text { Above }_{i}\right)+\beta_{2}\left(\text { ScoreDis } \tan \text { ce }_{i} * \text { Above }_{i} * \text { CollegeFE }\right) \\
& \text { (2) } \quad+\beta_{2}\left(\text { ScoreDis } \tan \text { ce }_{i} * \text { Below }_{i} * \text { CollegeFE }\right) \\
& +X_{i} \delta+\text { CollegeFE }+ \text { CohortFE }+\varepsilon_{i}
\end{aligned}
$$

where $Y$ is an outcome (measured over three years of follow-up, unless otherwise indicated) such as ever enrolled, number of semesters enrolled, number of credits accumulated, or whether the student ever completed a degree or transferred; Above is a binary indicator of whether or not the student scored above the relevant cutoff in that institution, year, and subject; ScoreDistance is the difference between the student's actual score and the relevant cutoff score in that institution, year, and subject; $\boldsymbol{X}$ is a vector of individual-level covariates including binary indicators for gender, race/ethnicity, language minority status, whether or not the student graduated from a local high school, as well as continuous measures of age and years since high school graduation; CollegeFE is a vector of college fixed effects, important since the treatment assignment is determined by the particular policies of each college; and CohortFE is a vector of test cohort fixed effects. Note that the coefficient on ScoreDistance is allowed to vary both across institutions, as well as above and below the cutoff.

The rationale for a local linear approach is that the alternative global methods focus energy on estimating the relationship between the test score and outcomes for ranges of the score 
that are far from the cutoff and which thus may provide little information about the regression function at the cutoff. As bandwidth is restricted to be closer to the cutoff, higher order terms in the regression function become less necessary and in fact may lead to excessive sensitivity around the cutoff. Nonetheless, we test the robustness of our results to variations in bandwidth as well as the addition of quadratic terms and also examine graphical plots of the data as a check on the specification.

Because of variations in the test format across subjects and over time, and because of differences in where the cutoffs are placed at each school, the precise estimating equation is different for math and English. In math, because two different tests were in place over the time period, we further separate the ScoreDistance controls depending upon whether the student took the old or the new test:

$$
\begin{aligned}
& Y_{i}=\alpha+\beta_{1}\left(\text { Above }_{i}\right)+\beta_{2}\left(\text { OldScoreDis } \tan c e_{i} * \text { Above }_{i} * \text { CollegeFE }\right) \\
& +\beta_{2}\left(\text { OldScoreDis tan ce }{ }_{i}^{*} \text { Below }_{i}^{*} \text { CollegeFE }\right) \\
& \text { (3) } \quad+\beta_{2}\left(\text { NewScoreDis } \tan \text { ce }_{i} * \text { Above }_{i} * \text { CollegeFE }\right) \\
& +\beta_{2}\left(\text { NewScoreDis tance }{ }_{i} * \text { Below }_{i} * \text { CollegeFE }\right) \\
& +X_{i} \delta+\text { CollegeFE }+ \text { CohortFE }+\varepsilon_{i}
\end{aligned}
$$

In the above, note that the cohort fixed effects absorb the main effects of test version. In addition, for those cohorts who took the new math test, the Above and ScoreDistance variables are based on the cutoffs for the more stringent of the two math modules (algebra) and the sample is restricted to those students that passed the easier of the two math modules (numerical skills/prealgebra). ${ }^{13}$ The resulting $\beta_{1}$ is (nearly) equivalent to running separate RDs within each college and test version, and then taking the weighted average of the impact estimates. ${ }^{14}$ We also show

\footnotetext{
${ }^{13}$ Students must pass both math modules to be placed directly into college-level; however, in practice the vast majority of students who are near the cutoff on the easier module fail the harder module. In other words, the cutoff policy on the harder (algebra) module is the primary determinant of college-level versus remedial assignment. ${ }^{14}$ With the minor difference that the pooled regression in (3) restricts the college fixed effects and student covariates to have the same effect across cohorts/test version.
} 
results separately by test version, since the cutoffs for the two exams fell at different points in the ability distribution.

To be placed into college-level English, students are required to pass both a reading test and a more difficult writing test. The writing test is the stronger determinant of college-level placement, since the majority of those near the cutoff in reading would fail the writing test anyway. Unfortunately, however, the writing test is graded on a limited 0-12 scale with each score unit representing a potentially large difference in underlying ability. Moreover, this final scale represents the sum of scores from two exam graders who are encouraged to agree on their scores, resulting in a discontinuous distribution of scores around the cutoff of 7.

Thus, we undertake two analyses in English, both focused on students scoring near the reading test cutoff: first, we limit the sample to those who failed the writing exam and look at the impact of being assigned to remediation in reading plus writing instead of writing alone; second, we limit the sample to those who passed the writing exam and look at the impact of being assigned to remediation in reading versus being assigned to college-level English. Although this is a relatively rare occurrence (only 19 percent of those who passed the writing exam failed the easier reading exam), our large sample still generates sufficient power to identify meaningful impacts. Moreover, this latter analysis enables us to say something about the impact of remediation for students whose test scores may be an underestimate of their true ability (conditional on passing the writing exam, the likelihood that a failing score on the reading exam results is a "mistake" increases). For both of these analyses, the estimating equation follows equation (2) where Above and ScoreDistance are both computed from the reading score.

Finally, as noted above, all of our analyses focus on estimating the effect of remedial assignment rather than the effect of enrollment in remediation per se. This stands in contrast to 
prior studies which have used an instrumental variables or "fuzzy" regression discontinuity design in which cutoff-based remedial assignments are used as an instrument for actual remedial enrollment (Calcagno \& Long, 2008; Martorell \& McFarlin, 2011). A key assumption needed to justify such an approach is that remedial assignment has no effect on future outcomes except through its effect on remedial enrollment; however, in many contexts including LUCCS this assumption is unlikely to hold. For example, a student assigned to remediation may opt not to enroll at all; a student who enrolls may find their access to college-level coursework restricted, and will not be able to graduate, even if they never enroll in a remedial course. Thus we maintain that the assignment itself is the relevant treatment (nevertheless, someone willing to make the necessary assumptions can still ballpark the IV estimates by dividing any of our impact estimates by our estimated "first stage" impacts on remedial enrollment).

\section{FULL SAMPLE RESULTS}

\section{A. Graphical Analysis and Specification Checks}

We begin by presenting graphical evidence to support the RD assumptions. First, we plot the distributions of the test scores to check for discontinuities in the density at the cutoff. Discontinuities in the density at the cutoff may suggest either that students are systematically sorting themselves around the cutoff (this is more of a concern in contexts that allow for retesting) or that some sample selection is taking place after students learn their scores (again this is more of a concern in contexts in which researchers may not have data on students who never enroll). In any case, we see little visual evidence of any discontinuities in the four distributions presented in Figure 1. For each distribution we run McCrary (2008) tests for discontinuities in the density and find none (results available upon request). 
Second, we examine graphical plots of several pre-treatment covariates by test score in Figures 2-5, and run the corresponding regressions to test for discontinuities (in math, although we show plots for the old and new math tests separately, we run a single pooled regression in the form of equation (3) above except with each covariate as the dependent variable, no covariates included in the regression, and bandwidth restricted to $+/-6$ points). The regressions confirm what the graphs suggest: no systematic differences in covariates around the cutoff. The only covariate for which we find a statistically significant difference is for high school preparatory units around the math cutoff; the regression indicates those below the cutoff have 0.34 additional high school preparatory units $(\mathrm{p}=0.03)$. However, a single significant (but still substantively small) difference among the dozen of covariates tested provides little cause for concern.

Finally, we examine graphical plots of several key outcomes by test score for visual evidence of discontinuities at the cutoff, shown in Figures 6-9. Overall, the graphs provide little indication that assignment to remediation affects the initial enrollment decision or the number of semesters enrolled over the subsequent three years. There is some hint of possible negative effects on degree/transfer mirrored by possible positive effects on dropout. The clearest pattern coming out of these graphs is that those scoring just below the cutoffs are substantially more likely to take remedial coursework, and somewhat less likely to take, pass, or do well in collegelevel coursework in the relevant subject.

\section{B. Main Results}

Assignment to remedial versus college-level math. Main results from the analysis of remedial math assignment are presented in Table 2. Our main specification utilizes a local linear regression with a bandwidth of $+/-6$ points; however, to test the sensitivity of our results we also show results with and without covariates, with a narrower local linear specification, and with a 
wider bandwidth that includes quadratic terms for all of the test score distance variables. Overall, the estimated effects are highly robust across these alternative specifications.

We find little evidence for discouragement effects on initial enrollment. While the results indicate that assignment to math remediation has a small, statistically significant negative effect on immediate enrollment (-2 percentage points), this fades out such that there is no impact on whether students enroll within three years. Thus, students assigned to remediation may delay enrollment but it does not appear to discourage them from enrolling ultimately. Moreover, some students who delay enrollment may in fact have been recruited into non-credit skills remediation programs. For example, LUCCS offers several intensive non-credit college transition programs for improving math and English skills, and students recruited into these programs may defer formal enrollment but still remain attached to the institution.

Nor do we find any indication of either development or discouragement effects postenrollment: assignment to remediation has little influence, either positive or negative, on degree completion, degree/transfer, persistence, dropout, or semesters enrolled. Further, we find no evidence that students learned more in remediation, as measured by outcomes on a standardized proficiency exam required in order to earn a two- or four-year degree. We find no impact on rates of taking or passing the college exit exam; for the 17 percent of students who took the exam we find no impact on their scores. ${ }^{15}$

The only outcomes for which we see a consistent pattern of impacts are those relating to the specific courses students take: assignment to math remediation increases the probability of taking remedial math by 27 percentage points, and decreases the probability of taking college

\footnotetext{
${ }^{15}$ The impacts on proficiency test scores are not strictly causal because they are conditional on a post-treatment outcome (taking the exam). However, if we make the assumption that any impact of treatment on test-taking is monotonic across individuals, then the fact that there is no overall impact on test-taking enables us to interpret the score differences — or or lack thereof — causally (Lee, 2009).
} 
level math by about 8 percentage points. Similarly, those assigned to math remediation were 5 percentage points less likely to pass college-level math, 4 percentage points less likely to ever earn a $\mathrm{C}$ or better, and 2 percentage points less likely to ever earn a B or better in college-level math. If one is willing to assume that the impacts on the B-or-better outcome result purely from the reduction in college-level coursetaking — and not from actual negative impacts on the academic potential of students who would have taken college-level coursework anyway-this implies that approximately one-quarter of the students diverted out of college-level courses could have earned a least a B there. Those assigned to remediation earn slightly more total "equated" credits (including remedial coursework) over three years, but this is driven entirely by remedial coursework - there is no impact on college-level credits accumulated.

Assignment to reading \& writing remediation versus writing-only remediation. This analysis, in which all students are assigned to writing remediation but some are additionally assigned to remediation in reading, finds similarly little evidence of effects on longer-term college outcomes such as degree/transfer, persistence, dropout, and taking/passing the college exit exam (see Table 3). Unlike the math analysis, we see no evidence here of diversion effects on the likelihood of taking, passing, or doing well in the relevant college-level course. This may be because students who fail the writing exam and are near the cutoff on the reading exam are unlikely to make it to college-level English regardless of their reading placement. Beyond a large impact on the likelihood of taking remedial reading, the only other positive impact is on ever taking remedial writing. This is likely due to the fact that some colleges at LUCCS bundle remedial reading and writing into a single course; such courses are identified in our dataset as remedial writing. There is a small 3.2 percentage point increase in the likelihood of immediate enrollment - the exact opposite of a discouragement effect-possibly as a result of concerted 
outreach programs for multiply-remediated students to complete these requirements as quickly as possible. But again this impact fades out such there is no enrollment effect, positive or negative, after three years.

Assignment to reading-only remediation versus college-level English. The sample sizes for this analysis, presented in Table 4, are significantly smaller because it is a relatively unusual occurrence for someone to fail the reading test but pass the relatively more difficult writing exam. Given the noise inherent in placement exams, we interpret this unusual pattern as suggestive evidence that these students' reading scores may be an underrepresentation of their true ability. ${ }^{16}$ For this group, we identify large and significant negative effects of remedial assignment on the likelihood of ever taking, passing, or doing relatively well in college-level English courses. In addition to these "diversion" effects we also see evidence of "discouragement" effects: we find negative effects on college-level credits completed and three year degree attainment and a positive effect on dropping-out—specifically, students placed in remedial reading versus college-level English are 5 percentage points less likely to earn an associate degree, 8 percentage points more likely to drop out and earn four fewer college-level credits (significant at the $10 \%$ level). Moreover, although it is not statistically significant, we see a small 3 percentage point decline in immediate enrollment that does not fade out but if anything gets slightly bigger after 3 years (though it remains statistically insignificant in all but one specification).

It is interesting to note that the negative impact on earning a B or higher in college-level English is a full 9 percentage points, only slightly smaller than the 12 percentage point negative

\footnotetext{
${ }^{16}$ While it is easy to think of reasons why a student may underperform on the computer-adaptive reading exam (unfamiliarity with adaptive tests; lack of awareness that a test would be required that day; distractions or time constraints at the test center), it seems less plausible that random noise would cause a student to perform far better than her true ability on the written essay exam.
} 
impact on ever taking college-level English. This suggests that the majority of students who were prevented from college-level English as a result of remedial assignment are students who could have done reasonably well in the course. This may be because for students who passed the writing exam, a failing score on the reading test may simply be the result of measurement error rather than evidence of inadequate preparation.

\section{Additional Findings}

Under the developmental model of remediation, students may experience an initial delay in accessing college-level coursework but the hope is that this will pay out over the longer term. It is possible that a three-year follow-up time frame is too short to observe these hypothesized positive effects, especially since some students may attend part-time (though the vast majority of students in this sample - over 85 percent — enroll full time at least for their first semester). Thus, for those students for whom longer follow-up data are available we examine degree/transfer, persistence, and dropout after five years. We find no evidence of significant effects on these outcomes emerging as we extend the follow up period. This is unsurprising as the majority of the sample has already dropped out by the end of the original three-year follow-up period.

\section{HETEROGENEITY BY TEST SCORE AND ACADEMIC RISK}

In math, we have large enough samples to support two subgroup analyses. We first examine the math results separately for students assigned on the basis of the old versus the new math test, as Figures 6 and 7 indicate possibly different patterns of effects. Second, we examine results for three risk subgroups, where we define risk as the probability of dropping out within two years based on demographic and high school background characteristics. [We also examined 
the reading results for these risk subgroups and note our findings below, but the much smaller sample sizes for those analyses makes them inconclusive.]

\section{A. Heterogeneity by Math Test Type}

Table 5 presents the results separately for those cohorts tested using the old test (2001-02 through 2003-04) and those tested using the new test (2004-05 through 2007-08). Recall that the new math test has two modules (both of which students must pass), and that our analysis focuses on students who passed the easier module and were near the cutoff on the harder module. This explains why the sample size is smaller for the new test compared to the old test, which utilized a single score to determine placement.

Broadly, the pattern of effects is similar regardless of the test in place. We do find, however, that both the impact on ever enrolling in developmental math as well as the estimated negative effects on some subsequent outcomes appear to be somewhat larger under the new test. Note that these results do not necessarily imply that the old test was somehow better than the new test, or that the remedial practices in place during 2001-2003 were somehow more effective (or less harmful) than those in place during 2004-2007. Because each set of estimates applies only to students near the cutoff on the relevant test, we interpret the difference in results as indicating heterogeneous effects of remedial assignment for students at different points in the ability distribution. When the math test changed, the cutoff effectively increased, resulting in an 11 percentage point increase in math remedial assignment rates between 2003 and 2004 (from 66 to 77 percent assigned to remediation). Thus, students on the margin of remediation under the new test are likely of higher average ability than those on the margin of remediation under the old test. This may also explain why only about 20 percent of students just above the cutoff on the new test enrolled in remediation voluntarily, compared to about 40 percent of students just above 
the cutoff on the old test. ${ }^{17}$ Note, however, that the larger negative effects for the new test cannot all be explained simply by pointing to a larger "first stage" effect on ever enrolling in remediation; while the impact on remedial coursetaking increases by 65 percent, the negative impacts on ever passing, earning a $\mathrm{C}$ or higher, or earning a $\mathrm{B}$ or higher in college level math all more than double.

This is supported by examining the background characteristics of those within a few points of the old and new cutoffs: students near the new cutoff have higher high school test scores and more college-preparatory course units; they are also somewhat younger and more likely to have entered college immediately after high school. Neither the differences in background characteristics nor the differences in estimated impacts are dramatic; nonetheless these results suggest remedial assignment may be more harmful for students of higher ability.

\section{B. Heterogeneity by Prior Predicted Dropout Risk}

A way of exploring heterogeneity across students more directly is to examine results for student subgroups. Rather than look at subgroups defined by single dimensions (e.g. gender, age, high school coursework), we create a composite measure of dropout risk and then split the sample into high, medium, and low(er) risk subgroups. We do this by running a probit regression that predicts the likelihood of dropping out within two years:

(4) $\operatorname{Pr}($ Dropout $)=\alpha+X \delta+A \varphi+\varepsilon$

in which $\boldsymbol{X}$ is a vector of student characteristics including gender, race/ethnicity, age, language minority status, whether or not the student came from a local high school, and $\boldsymbol{A}$ is a vector of prior achievement including several measures of high school coursework (college preparatory units in math, English, science, social studies, and overall; grades in math, English, and

\footnotetext{
${ }^{17}$ By "voluntarily," we mean that remedial enrollment was not required as a matter of institutional policy for those scoring above the cutoff; however, it is possible that students may nonetheless have been strongly encouraged to take remediation even if they were above the cutoff.
} 
overall). ${ }^{18}$ We use the resulting regression parameters to predict each student's risk of dropout. Students are defined as high risk if they are in the top quartile of predicted risk (greater than 60 percent risk), medium risk if they fall in the middle 50 percent ( 45 to 60 percent risk), and low(er) risk if they are in the bottom quartile (under 40 percent risk). It is worth noting that in an absolute sense, even the "low risk" group has a relatively average high estimated probability of dropping out within two years (38 percent); this is important for thinking about how these results may generalize to other contexts (such as remediation at four-year colleges).

Results are presented in Table 6, with the full-sample results included in the first column for comparison. As in the full sample, there are no effects on degree completion/transfer, persistence, dropout, college-level credits, or taking/passing the college exit exam. The results suggest that high-risk students may be more likely to delay initial enrollment as a result of remedial assignment (either because of discouragement or because of diversion into non-credit basic skills interventions). On the college math course-taking outcomes, however, the results generally appear more negative for students with a lower-risk of dropping out. All subgroups experience a roughly 8-9 percentage point decline in the likelihood of ever taking college-level math, but the negative effects on ever passing college-level math, or ever earning a $\mathrm{C}$ or better in college level math, are almost twice as large in the lower-risk subgroup than in the other subgroups. Finally, the lower risk subgroup experiences a significant 4 percentage point decline in the likelihood of ever earning a B or better in college-level math, compared to an insignificant 2 percentage point decline in the medium risk subgroup and no decline in this measure in the highest risk subgroup.

\footnotetext{
${ }^{18}$ For the 10 percent of the sample for whom high school measures were unavailable, we zero-out the achievement measures and include a missing data flag in the regression.
} 
We also examined the reading plus writing and reading-only remediation analyses (Tables 3 and 4) by risk subgroup. In neither case did we see any clear pattern of subgroup differences. This may be because standard errors are larger for these subsamples, making it difficult to identify true differences; alternatively, the effects of these "treatments" in English could truly be more homogenous across subgroups. ${ }^{19}$

\section{DISCUSSION}

Our results add to prior evidence from similar studies in Texas (Martorell \& McFarlin, 2011) and Florida (Calcagno \& Long, 2008) that remediation does not sufficiently develop students' skills in order to improve their chances of college-level success. While a necessary caveat to any RD analysis is that these results only generalize to students near the threshold, it is also worth noting that our analysis examines two different subjects and aggregates impacts across multiple institutions, multiple years, and in the case of math, multiple tests —and in no case do we see any evidence of positive effects on college outcomes. Moreover, our analysis of high, medium, and low academic risk students who all scored near the threshold (in math) indicates that while the pattern of effects is somewhat more negative for lower-risk students, we fail to find any positive effects even for the highest-risk group.

Though we find little support for the developmental model of remediation, nor do we find much evidence that assignment to remediation results in the active discouragement that some have feared, at least in general. Students just below the remedial cutoffs (at least in LUCCS) in both math and our main reading analysis are no less likely to enroll, and stay enrolled for about

\footnotetext{
${ }^{19}$ For the analysis of reading-and-writing remediation versus reading-only remediation, we see little evidence of differences across subgroups. For the analysis of reading remediation versus college level English (for those who passed the writing exam), the sample size within subgroups creates very large standard errors particularly in the low and high risk groups; if anything, the pattern of results suggests slightly larger negative effects on the college English course-taking outcomes for the highest-risk subgroup. We do not present these results due to the large standard errors and lack of consistent subgroup patterns.
} 
the same number of terms as those just above the cutoff. If anything, students assigned to remediation take slightly more credits overall, although virtually all of these additional credits are in remedial courses.

For only one group do we find significant evidence of discouragement: students who were assigned to remedial reading even though they passed a writing exam. The fact that students passed a harder exam while barely failing an easier one suggests that their reading test scores may under-represent their true ability. For these students we find large but noisy negative effects on initial enrollment, large diversionary coursework effects, significant declines in degree receipt and increases in dropout. These particularly large effects may also be due in part to the fact that remedial assignment in English has more consequences for access to other college coursework (since Freshman Composition is a common prerequisite) than does remedial assignment in math. In any case, the results suggest that policymakers may want to pay more attention to the risk of mis-assigning prepared students to remediation, which research suggests is relatively common when test scores are used as the sole determinant of placement (ScottClayton, 2012; Belfield \& Crosta 2012).

Our results most closely fit the "diversion" model of remediation. The primary, most consistent pattern of effects we find relate to the specific courses that students take while they are enrolled: instead of taking college-level courses in the relevant subject, students take remedial courses. It is difficult to conclusively determine whether this is a bad thing without additional information. While we find no evidence that students learned more in the courses into which they were diverted, we cannot rule this out since our measure of student learning (college proficiency test scores) is somewhat limited by the fact that many students never even make it far enough to take the exam. Moreover, we do not know whether high rates of remediation may improve 
outcomes for non-remediated students, either through direct peer effects or by enabling institutions to reduce crowding in college-level courses.

There are three reasons to worry about these diversionary effects, however. First, the negative impacts in both the math and the second reading analysis on the proportion ever earning a B or better in the relevant college level course is concerning. It suggests that one-quarter of students diverted out of college level coursework in math, and up to 70 percent of diverted students in English $(0.70=10.9 / 15.5$, Table 4$)$ actually could have done quite well there had they been given the opportunity. Second, diversionary effects appear to be largest for students with the lowest predicted risk of dropping out, for whom the ability tracking and peer effects rationales for such diversion make the least sense.

Finally, if the primary revealed function of remediation is diversion rather than development, it implies that remedial courses may not be providing the optimal content. Many remedial courses are designed explicitly to prepare students for college-level coursework in the relevant subject, which our analysis suggests they may never take. For example, a remedial math course may require students to master quadratic equations even though they are unlikely to need that skill either in their future jobs or even in a "college-level" math course (Jaggars \& Hodara, 2011). A question for future research is what type of remedial curriculum is most valuable for students who may not continue beyond the course. 


\section{References}

ACT, Inc. (2006). COMPASS/ESL reference manual. Iowa City, IA: Author.

Belflield, C. \& Crosta P. M. (2012). Predicting Success in College: The Importance of Placement Tests and High School Transcripts (CCRC Working Paper No. 42). New York, NY: Columbia University, Teachers College, Community College Research Center.

Bettinger, E. \& Long, B.T. (2005). "Remediation at the Community College: Student Participation and Outcomes," New Directions for Community Colleges 129: 17-26.

Bettinger, E. \& Long, B. T. (2009). Addressing the needs of underprepared students in higher education: Does college remediation work? Journal of Human Resources, 44(3), 736771.

Boatman, A. \& Long, B. T. (2010). Does Remediation Work for All Students? How the Effects of Postsecondary Remedial and Developmental Courses Vary by Level of Academic Preparation (NCPR Working Paper). New York, NY: National Center for Postsecondary Research.

Burris, C. C., Hubert, J.P., \& Levin, H.M. (2006). Accelerating Mathematics Achievement Using Heterogeneous Grouping. American Educational Research Journal, 43(1), 105136.

Calcagno, J. C. \& Long, B. T. (2008). The impact of postsecondary remediation using a regression discontinuity approach: Addressing endogenous sorting and noncompliance (NBER Working Paper. No. 14194). Cambridge, MA: National Bureau of Economic Research.

Carrell, S., Fullerton, R., \& West, J. E. (2009). Does your Cohort Matter? Measuring Peer Effects in College Achievement. Journal of Labor Economics. 27(3), 439-464.

Clark, B. R. (1960). The "Cooling-Out" Function of Higher Education. American Journal of Sociology. 65(6), 569-576.

Dadgar, M. (2012). Essays on the Economics of Community College Students' Academic and Labor Market Success. (Doctoral dissertation). Retrieved from ProQuest Dissertations and Theses. (Accession Order No. [3506175]).

Delta Cost Project (2012). Trends in College Spending Online. Washington, DC: American Institutes for Research (www.tcs-online.org/Home.aspx [August 13, 2012]).

Figlio, D.N. \& Page, M.E. (2002). School Choice and the Distributional Effects of Ability Tracking: Does Separation Increase Inequality? Journal of Urban Economics, 51(3), 497514. 
Greene, J. \& Forster, G. (2003). Public High School Graduation and College Readiness Rates in the United States. (Education Working Paper No. 3). New York: Manhattan Institute for Policy Research, Center for Civic Innovation.

Hodara, M. (2012). Language Minority Students at Community College: How Do Developmental Education and English as a Second Language Affect Their Educational Outcomes? (Doctoral dissertation). Retrieved from ProQuest Dissertations and Theses. (Accession Order No. [3505981]).

Hughes, K. L. \& Scott-Clayton, J. (2011). Assessing Developmental Assessment in Community Colleges. (CCRC Working Paper No. 19). New York, NY: Columbia University, Teachers College, Community College Research Center.

Imbens, G. and Lemieux, T. (2008). Regression Discontinuity Designs: A Guide to Practice. Journal of Econometrics, 142(2), 615-635.

Jaggars, S. S. \& Hodara, M. (2011). The Opposing Forces that Shape Developmental Education: Assessment, Placement, and Progression at CUNY Community Colleges (CCRC Working Paper No. 36). New York, NY: Columbia University, Teachers College, Community College Research Center.

Lee, D. (2009). Training, Wages, and Sample Selection: Estimating Sharp Bounds on Treatment Effects. Review of Economic Studies 76, 1071-1102.

Manski, C. (1989). Schooling as Experimentation: A Reappraisal of the Postsecondary Dropout Phenomenon. Economics of Education Review 8 (4), 305-312.

Martorell, P., \& McFarlin, I. (2011). Help or hindrance? The effects of college remediation on academic and labor market outcomes. The Review of Economics and Statistics, 93(2), 436-454.

Martorell, P., McFarlin, I., \& Xue, Y. (2011). Does Failing a Placement Exam Discourage Underprepared Students from Going to College? (Working Paper \#11-14). Ann Arbor, MI: University of Michigan, National Poverty Center.

McCrary, J. (2008). Manipulation of the running variable in the regression discontinuity design: A density test. Journal of Econometrics, 142(2), 698-714.

National Center for Education Statistics (2012). BPS:2009 Beginning Postsecondary Students Database. Accessed via QuickStats (nces.ed.gov/datalab/quickstats/createtable.aspx [August 13, 2012]). Washington, DC: U.S. Department of Education.

Papay, J. P., Murnane, R. J., \& Willett, J. B. (2011). How Performance Information Affects Human-Capital Investment Decisions: The Impact of Test-Score Labels on Educational Outcomes (NBER Working Paper. No. 17120). Cambridge, MA: National Bureau of Economic Research. 
Peterson, J.M. (1989). Remediation is no remedy. Educational Leadership. 46(6). 24-25.

RP Group for California Community Colleges. (2007). Basic Skills as a Foundation for Student Success in California Community Colleges. Sacramento: RP Group for California Community Colleges.

Rubin, D. (1974). Estimating Causal Effects of Treatments in Randomized and Nonrandomized Studies. Journal of Educational Psychology, 66(5), 688-701.

Sacerdote, B. (2001). Peer Effects with Random Assignment: Results for Dartmouth Roomates. Quarterly Journal of Economics. 116(2), 681-704.

Scott-Clayton, J. (2012). Do High-Stakes Placement Exams Predict College Success? (CCRC Working Paper No. 41). New York, NY: Columbia University, Teachers College, Community College Research Center.

White, P., Gamoran, A., Porter, A. C., \& Smithson, J. (1996). Upgrading the high school mathematics curriculum: Mathematics course-taking patterns in seven high schools in California and New York. Educational Evaluation and Policy Analysis, 18 (4), 285-307.

Winston, G. C. \& Zimmerman, D. J. (2004). Peer Effects in Higher Education. In College Choices: The Economics of Where to Go, When to Go, and How to Pay for It, edited by C. Hoxby. Chicago: National Bureau of Economic Research and University of Chicago Press.

Zimmer, R. (2003). A New Twist in the Educational Tracking Debate. Economics of Education Review. 22(3), 307-315.

Zimmerman, D.J. (2003). Peer Effects in Academic Outcomes: Evidence from a Natural Experiment. Review of Economics and Statistics, 85(1), 9-23. 


\section{Figure 1. Distributions of test scores relative to school-year-specific cutoffs}

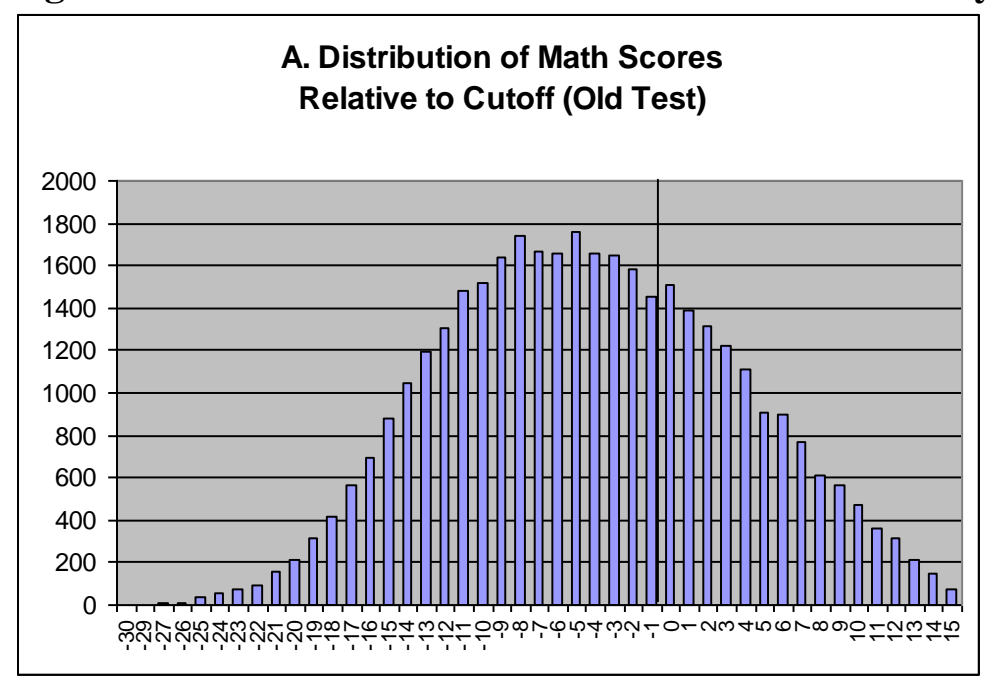

C. Distribution of Reading Scores, Failed Writing
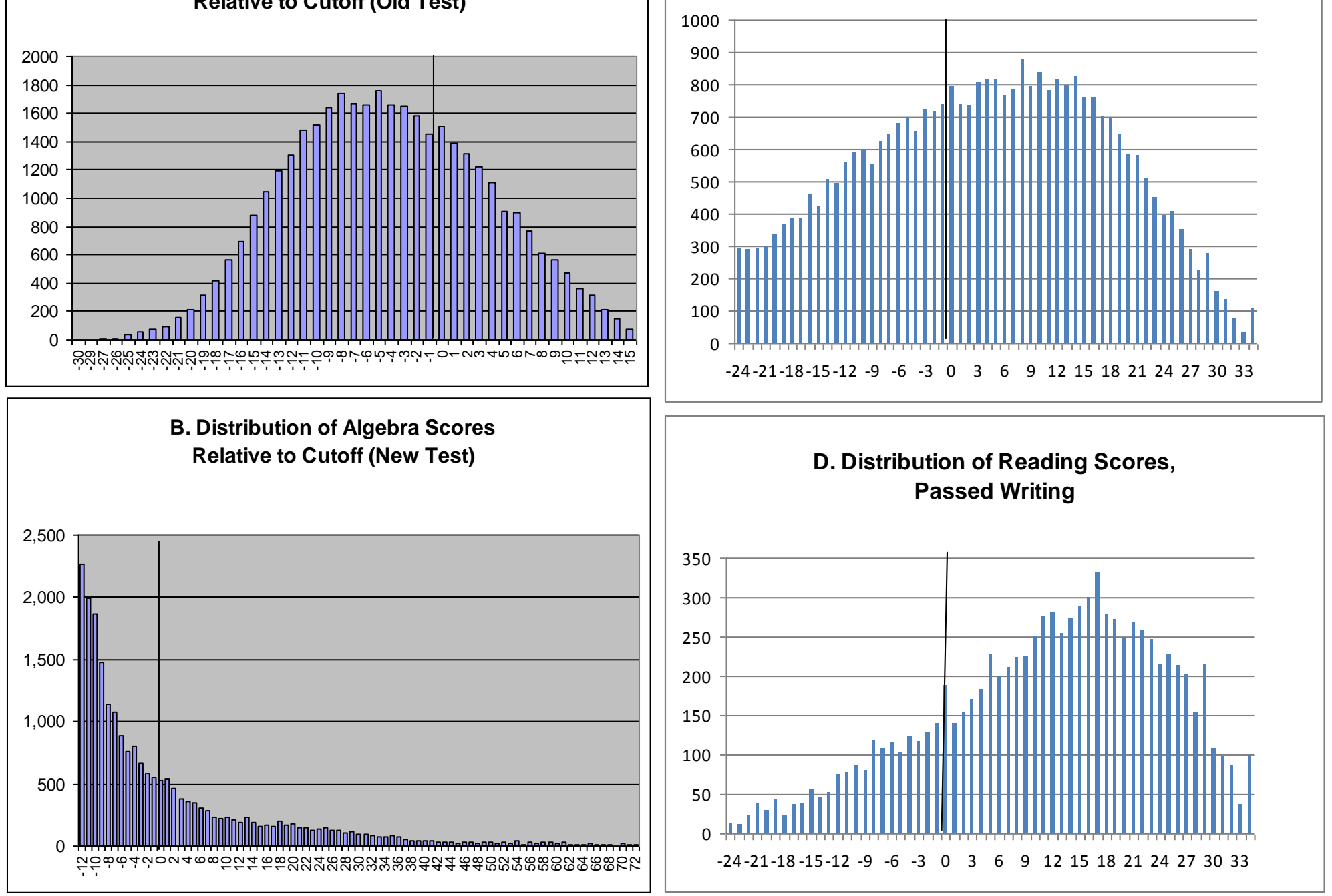

Notes: The old math test was a single test while the new math test has two modules. The harder of the two modules, algebra, is the most common determinant of college-level versus remedial placement in math. The sample in panel (B) is restricted to those who passed the easier math module. 
Figure 2. Covariates by test score relative to the cutoff, old math test.

\section{Covariates by Old Math Score Score}
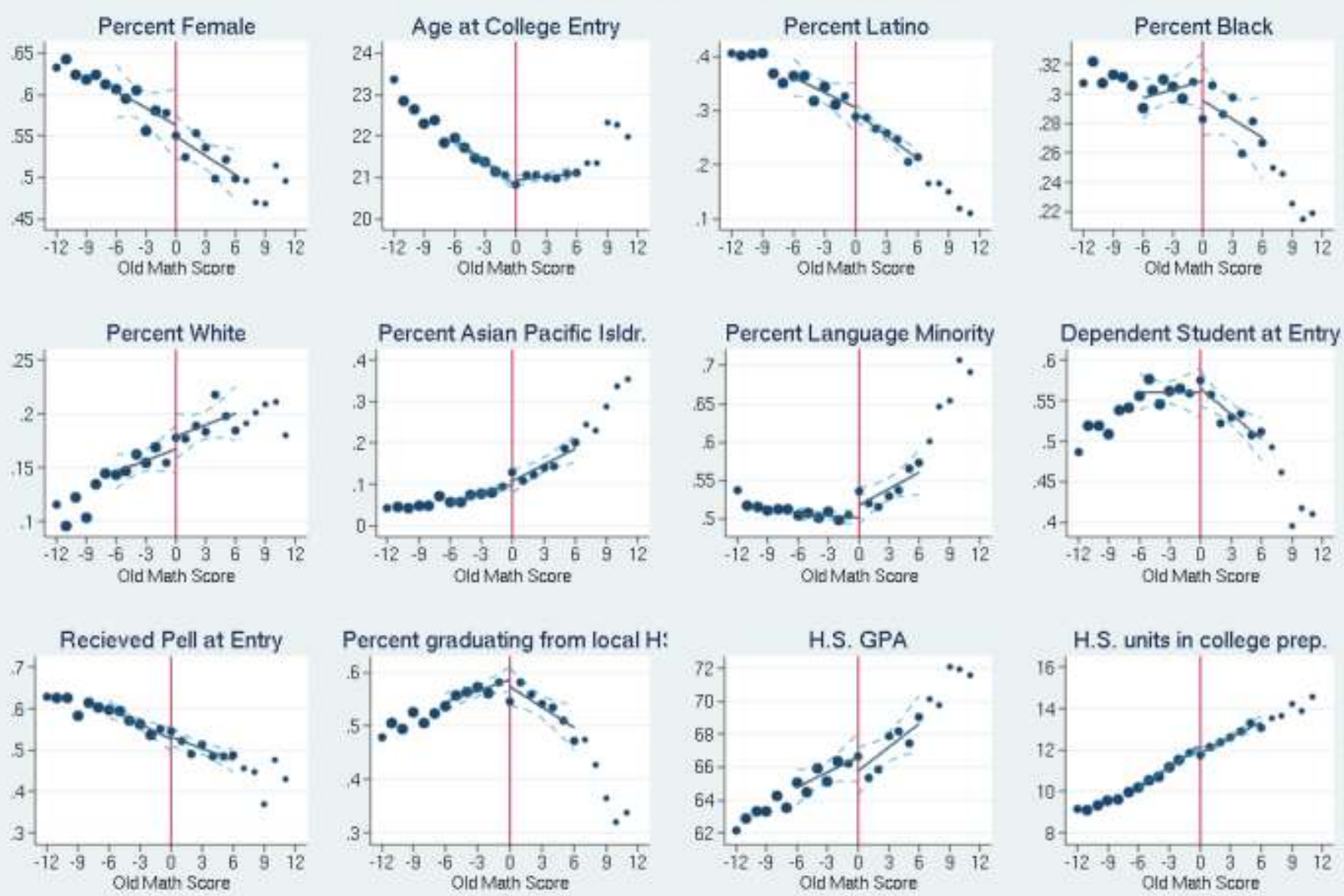
Figure 3. Covariates by Algebra ("Math 2") Score relative to the cutoff, new math test

\section{Covariates by Compass Math 2 Score}
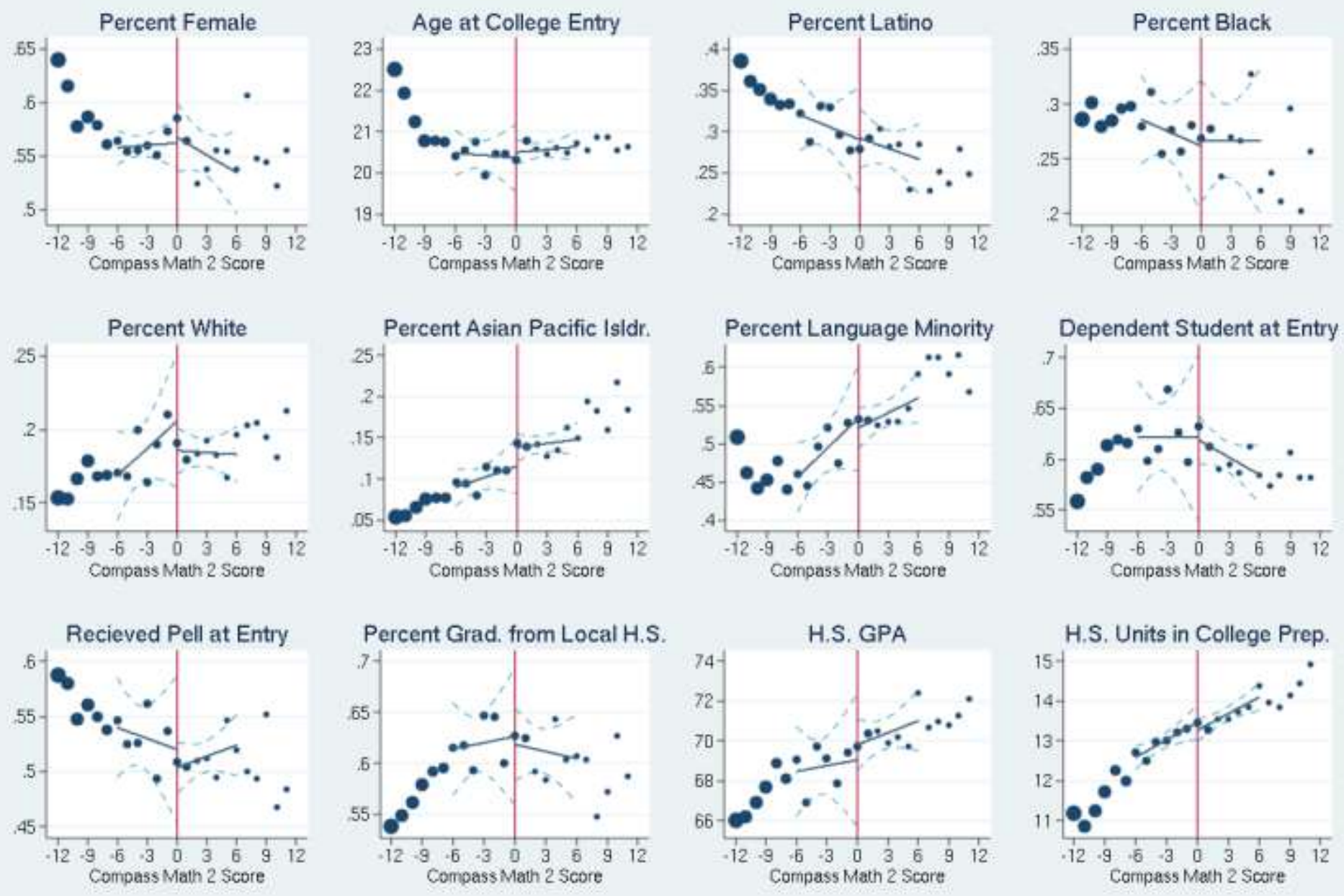

Notes: Sample for new math test is restricted to those who passed the easier of the two math modules. 
Figure 4. Covariates by reading test score, for those who failed writing.

\section{Covariates by Reading Score and Failed Writing}
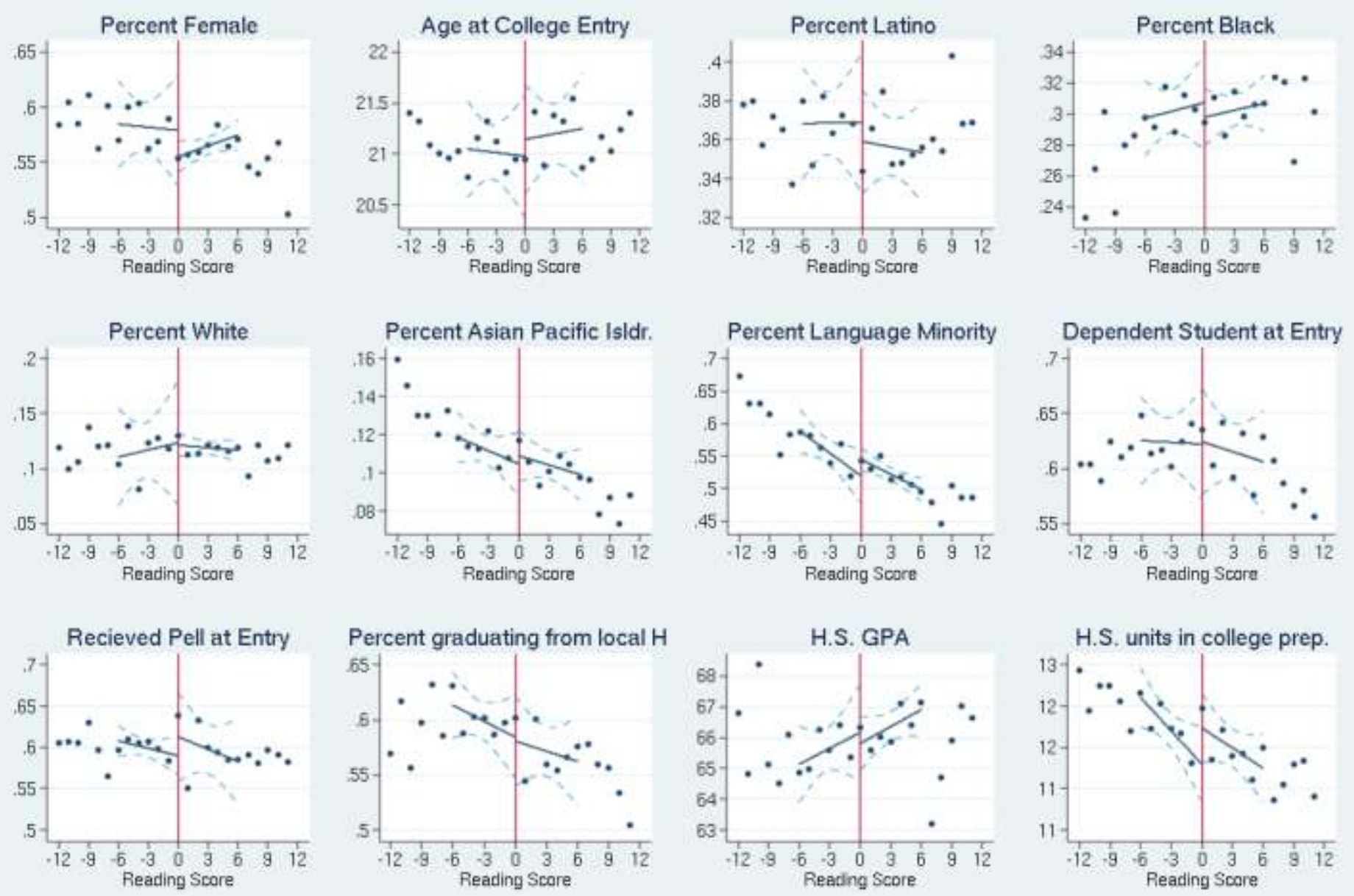
Figure 5. Covariates by reading test score, for those who passed writing.

\section{Covariates by Reading Score and Passed Writing}
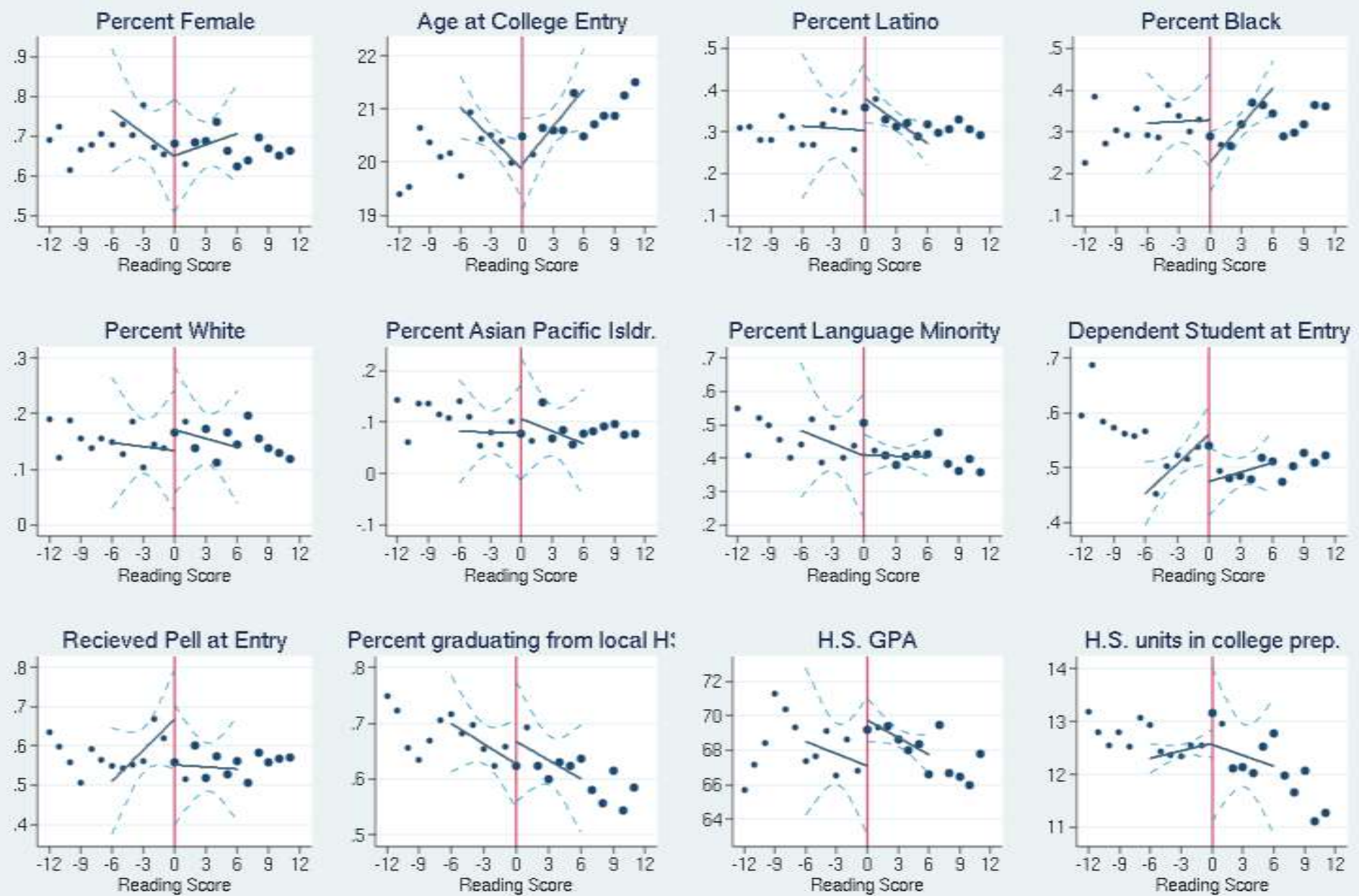
Figure 6. Outcomes by Old Math Test Score (2001-2004 cohorts).

\section{Outcomes by Old Math Score}
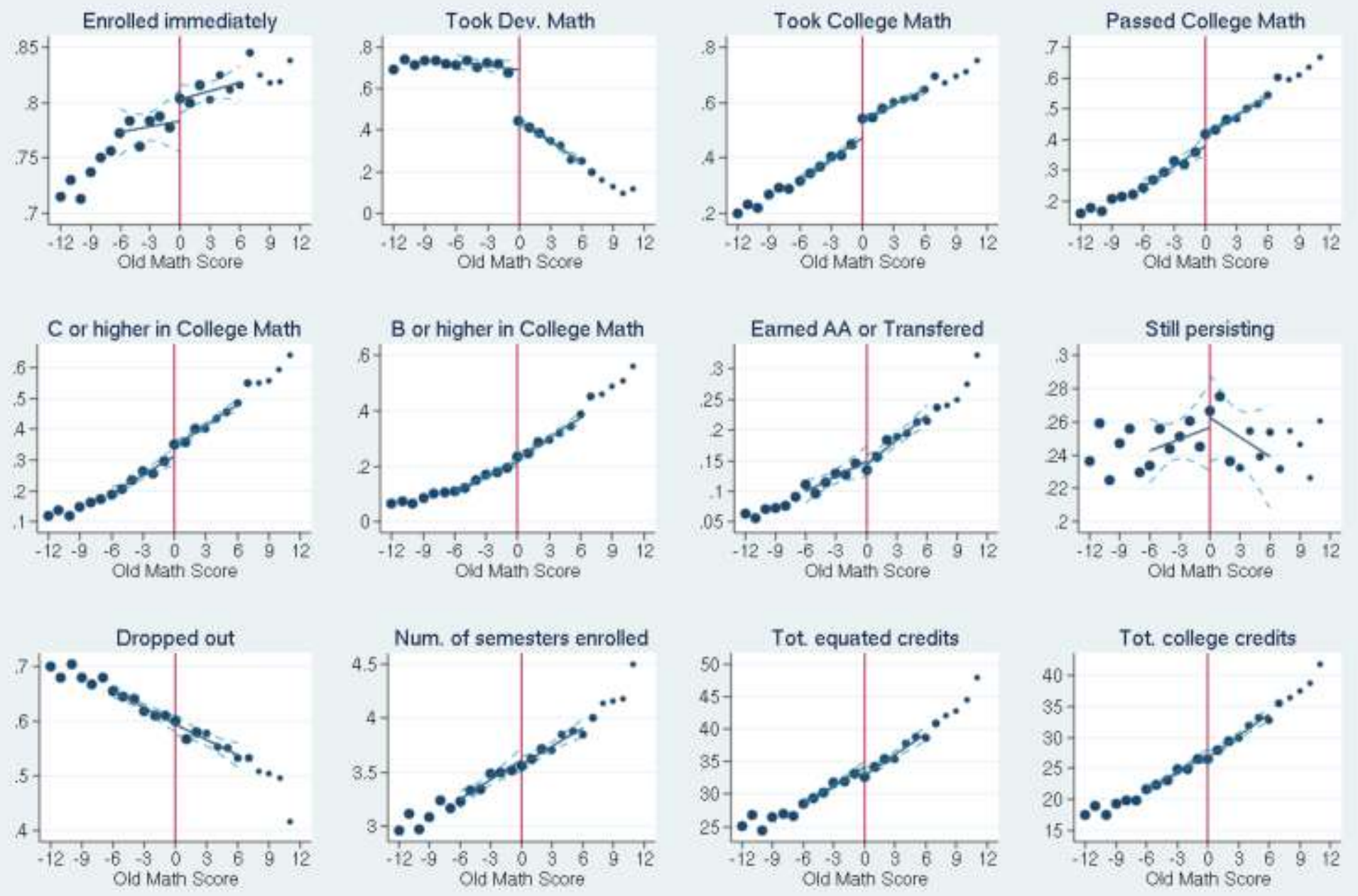
Figure 7. Outcomes by New Math Test Score (2004-2007 cohorts).

\section{Outcomes by Compass Math 2 Score}
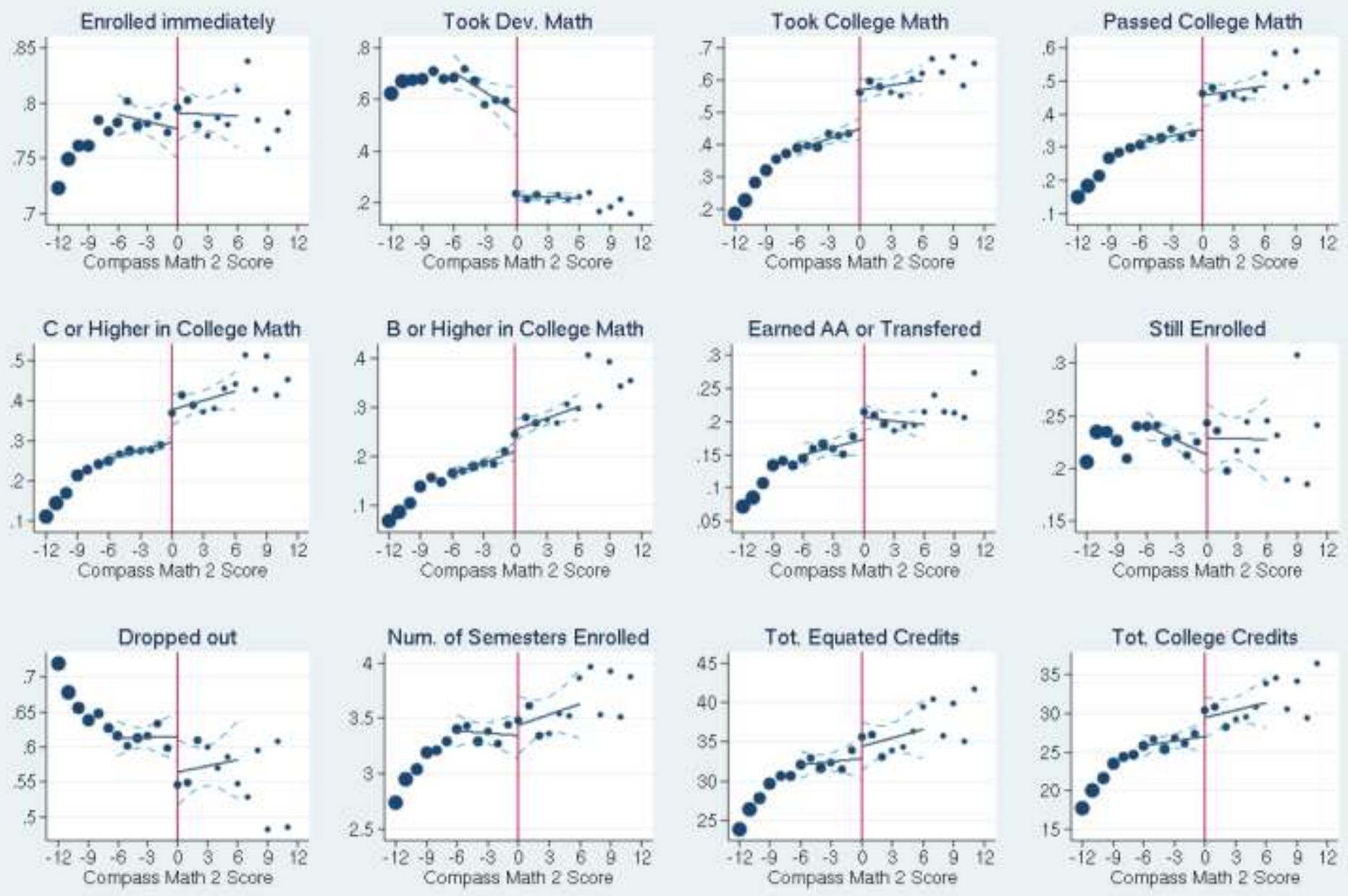
Figure 8. Outcomes by Reading Score for those who failed Writing.

\section{Outcomes by Reading Score and Failed Writing}
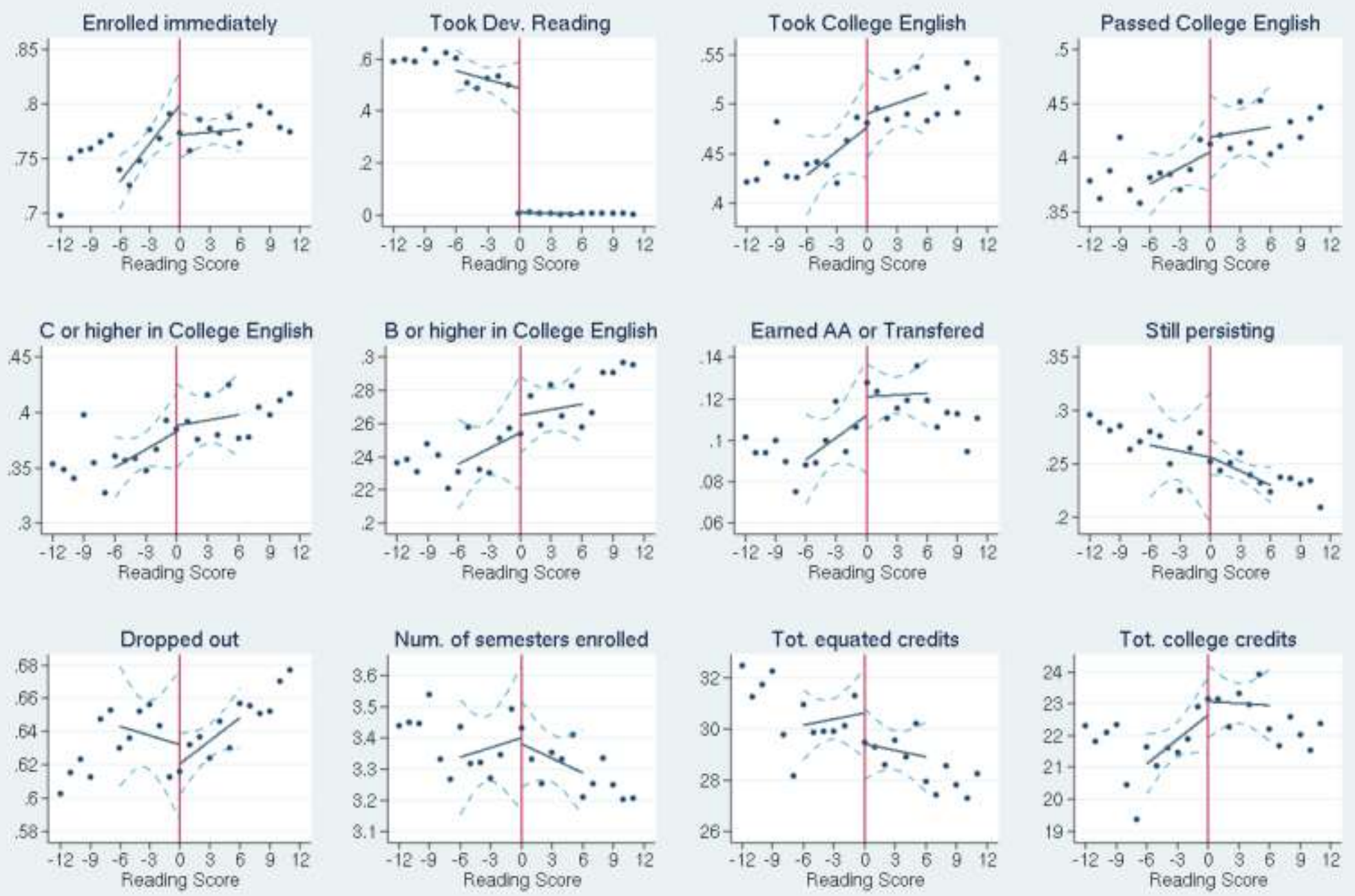
Figure 9. Outcomes by Reading Score for those who passed Writing.

\section{Outcomes by Reading Score and Passed Writing}
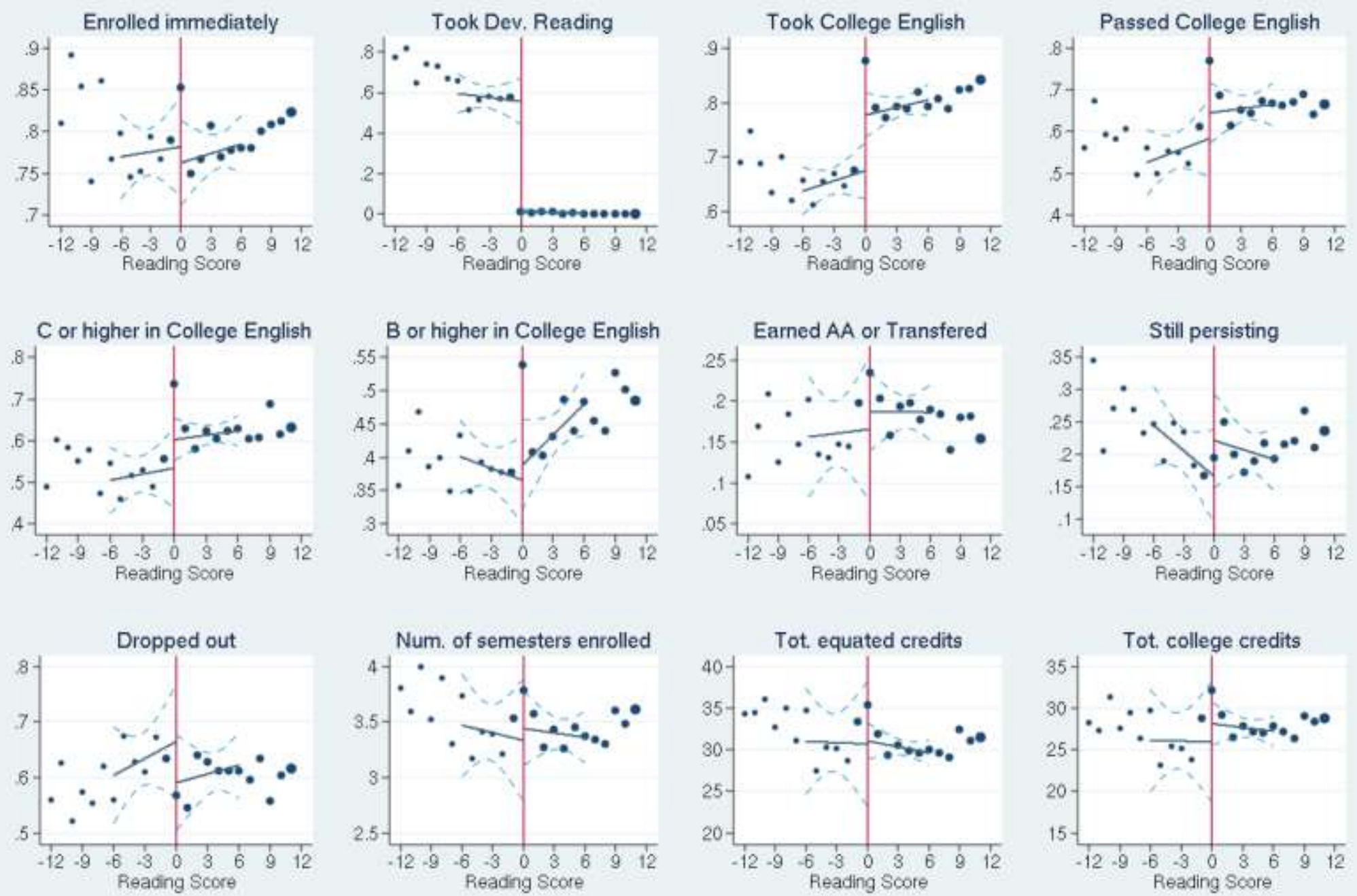


\begin{tabular}{|c|c|c|c|c|c|c|}
\hline & $\begin{array}{l}\text { All test- } \\
\text { takers }\end{array}$ & $\begin{array}{c}\text { No- } \\
\text { Remediation }\end{array}$ & $\begin{array}{l}\text { Remediation } \\
\text { in Any Subject }\end{array}$ & $\begin{array}{c}\text { Math } \\
\text { Analysis } \\
\text { Sample } \\
\text { (+/-4pts) }\end{array}$ & $\begin{array}{c}\text { Reading } \\
\text { Analysis, } \\
\text { Failed } \\
\text { Writing } \\
\text { (+/-4pts) }\end{array}$ & $\begin{array}{c}\text { Reading } \\
\text { Analysis, } \\
\text { Passed } \\
\text { Writing } \\
\text { (+/-4pts) }\end{array}$ \\
\hline Assigned to Dev Math, College Std. & 0.720 & 0.000 & 0.793 & 0.573 & 0.776 & 0.752 \\
\hline Assigned to Dev Writing College Std. & 0.719 & 0.000 & 0.792 & 0.660 & 1.000 & 0.000 \\
\hline Assigned to Dev Reading College Std. & 0.378 & 0.000 & 0.418 & 0.303 & 0.481 & 0.442 \\
\hline Assigned to Any Dev Ed., College Std. & 0.901 & 0.000 & 1.000 & 0.851 & 1.000 & 0.840 \\
\hline Female & 0.578 & 0.562 & 0.580 & 0.561 & 0.569 & 0.683 \\
\hline Age & 21.585 & 20.102 & 21.712 & 20.941 & 21.104 & 20.408 \\
\hline White, Non-Hispanic & 0.142 & 0.233 & 0.134 & 0.176 & 0.116 & 0.156 \\
\hline Black, Non-Hispanic & 0.282 & 0.280 & 0.282 & 0.290 & 0.303 & 0.306 \\
\hline Latino & 0.343 & 0.231 & 0.354 & 0.303 & 0.365 & 0.331 \\
\hline Asian Pacific Islander & 0.106 & 0.116 & 0.106 & 0.106 & 0.108 & 0.082 \\
\hline Other Race & 0.067 & 0.067 & 0.066 & 0.061 & 0.062 & 0.068 \\
\hline Language Minority & 0.527 & 0.426 & 0.537 & 0.514 & 0.540 & 0.429 \\
\hline Graduated from Local High School & 0.551 & 0.653 & 0.543 & 0.579 & 0.586 & 0.643 \\
\hline Years delayed enrollment & 2.664 & 1.838 & 2.728 & 2.269 & 2.182 & 1.728 \\
\hline HS GPA (0-100 scale) & 73.558 & 75.705 & 73.343 & 73.526 & 72.704 & 73.343 \\
\hline HS College Prep Units & 11.737 & 14.452 & 11.509 & 12.158 & 11.642 & 12.531 \\
\hline Has HS GPA & 0.904 & 0.942 & 0.901 & 0.913 & 0.907 & 0.934 \\
\hline Four-year college is 1st Choice & 0.294 & 0.394 & 0.285 & 0.296 & 0.313 & 0.390 \\
\hline Full-time Enrollment at Entry & 0.859 & 0.870 & 0.859 & 0.866 & 0.869 & 0.857 \\
\hline Received Pell at Entry & 0.569 & 0.455 & 0.582 & 0.534 & 0.602 & 0.572 \\
\hline Missing Pell Data & 0.170 & 0.113 & 0.174 & 0.131 & 0.161 & 0.160 \\
\hline Dependent at Entry & 0.737 & 0.837 & 0.729 & 0.774 & 0.776 & 0.787 \\
\hline Missing Dependency Data & 0.366 & 0.392 & 0.361 & 0.359 & 0.331 & 0.353 \\
\hline Enrolled immediately & 0.750 & 0.837 & 0.743 & 0.789 & 0.773 & 0.787 \\
\hline Enrolled w/in 3 & 0.829 & 0.886 & 0.825 & 0.866 & 0.838 & 0.840 \\
\hline Took Dev. Math w/in 3 & 0.547 & 0.195 & 0.581 & 0.533 & 0.578 & 0.587 \\
\hline Took College Math w/in 3 & 0.367 & 0.642 & 0.342 & 0.481 & 0.352 & 0.385 \\
\hline Passed College Math & 0.299 & 0.536 & 0.277 & 0.382 & 0.290 & 0.319 \\
\hline C or Higher in College Math & 0.249 & 0.469 & 0.229 & 0.317 & 0.240 & 0.268 \\
\hline B or Higher in College Math & 0.176 & 0.363 & 0.158 & 0.217 & 0.163 & 0.171 \\
\hline Took Dev. Writing w/in 3 & 0.487 & 0.006 & 0.533 & 0.458 & 0.709 & 0.015 \\
\hline Took Dev. Reading w/in 3 & 0.219 & 0.002 & 0.241 & 0.179 & 0.251 & 0.258 \\
\hline Took College English w/in 3 & 0.534 & 0.856 & 0.504 & 0.611 & 0.477 & 0.745 \\
\hline Passed College English & 0.451 & 0.742 & 0.424 & 0.519 & 0.408 & 0.628 \\
\hline C or Higher in College English & 0.425 & 0.720 & 0.398 & 0.492 & 0.380 & 0.591 \\
\hline B or Higher in College English & 0.310 & 0.596 & 0.284 & 0.364 & 0.256 & 0.418 \\
\hline Earned $\mathrm{AA}$ or $\mathrm{BA}$ w/in 3 & 0.092 & 0.220 & 0.080 & 0.115 & 0.084 & 0.136 \\
\hline Transferred or Earned Degree w/in 3 & 0.124 & 0.294 & 0.109 & 0.155 & 0.112 & 0.180 \\
\hline Still Enrolled at End of Year 3 & 0.240 & 0.191 & 0.245 & 0.244 & 0.253 & 0.205 \\
\hline Dropped Out in Year 3 & 0.635 & 0.516 & 0.645 & 0.601 & 0.634 & 0.615 \\
\hline Number of terms enrolled w/in 3 & 3.297 & 3.882 & 3.249 & 3.503 & 3.351 & 3.463 \\
\hline Tot. Equated Credits Passed in 3 & 29.761 & 39.009 & 28.967 & 33.036 & 29.762 & 31.347 \\
\hline Tot. College Credits Passed in 3 & 23.347 & 37.504 & 22.072 & 26.811 & 22.507 & 27.607 \\
\hline Took CPE w/in 3 & 0.142 & 0.315 & 0.126 & 0.172 & 0.130 & 0.209 \\
\hline Pass CPE w/in 3 & 0.129 & 0.302 & 0.114 & 0.157 & 0.116 & 0.197 \\
\hline CPE Highest Score w/in 3 & 42.427 & 44.789 & 41.899 & 42.045 & 41.611 & 42.899 \\
\hline Sample Size & 100,250 & 7,592 & 90,342 & 18,724 & 7,049 & 1,374 \\
\hline
\end{tabular}


Table 2. Main Results: Effects of Assignment to Math Remediation

\begin{tabular}{|c|c|c|c|c|c|c|c|}
\hline \multirow[b]{2}{*}{ Outcome } & $\begin{array}{c}\text { Main } \\
\text { Specification }\end{array}$ & \multicolumn{2}{|l|}{$\begin{array}{c}\text { No } \\
\text { Covariates }\end{array}$} & \multicolumn{2}{|l|}{$\begin{array}{c}\text { Narrow } \\
\text { Bandwidth }\end{array}$} & \multicolumn{2}{|l|}{$\begin{array}{c}\text { Wide } \\
\text { Bandwidth }\end{array}$} \\
\hline & $(\mathrm{SE})$ & $(\mathrm{SE})$ & & (SE) & & $(\mathrm{SE})$ & \\
\hline Enrolled immediately & $-0.020(0.010) * *$ & $-0.020(0.010)$ & ** & $-0.012(0.013)$ & & $-0.021(0.011)$ * & \\
\hline Enrolled w/in 3 years & $-0.004(0.008)$ & $-0.004(0.008)$ & & $-0.006(0.011)$ & & $-0.013(0.009)$ & \\
\hline Took dev math & $0.273(0.011)^{* * *}$ & $0.274(0.011)$ & $* * *$ & $0.279(0.014)$ & $* * *$ & $0.257(0.012)$ * & *** \\
\hline Took college-level math & $-0.077(0.012) * * *$ & $-0.077(0.012)$ & *** & $-0.075(0.015)$ & $* * *$ & $-0.081(0.013)$ * & *** \\
\hline Passed college-level math & $-0.050(0.012) * * *$ & $-0.051(0.012)$ & $* \star *$ & $-0.059(0.015)$ & $\star \star \star *$ & $-0.048(0.013)$ * & *** \\
\hline Earned $\mathrm{C}$ or higher in $\mathrm{CL}$ math & $-0.043(0.011) * * *$ & $-0.045(0.011)$ & $\star \star \star$ & $-0.050(0.014)$ & $* \star \star$ & $-0.040(0.012)$ * & *** \\
\hline Earned $\mathrm{B}$ or higher in CL math & $-0.021(0.010)$ ** & $-0.023(0.010)$ & ** & $-0.023(0.012)$ & * & $-0.019(0.011)$ * & * \\
\hline Earned AA & $-0.002(0.008)$ & $-0.002(0.008)$ & & $-0.001(0.010)$ & & $-0.005(0.008)$ & \\
\hline Earned AA or transferred & $-0.002(0.009)$ & $-0.001(0.009)$ & & $0.002(0.011)$ & & $-0.004(0.009)$ & \\
\hline Still persisting & $-0.008(0.011)$ & $-0.009(0.011)$ & & $-0.016(0.013)$ & & $-0.010(0.012)$ & \\
\hline Dropped out & $0.010(0.012)$ & $0.011(0.012)$ & & $0.013(0.015)$ & & $0.015(0.013)$ & \\
\hline Semesters enrolled & $0.031(0.060)$ & $0.026(0.061)$ & & $0.033(0.075)$ & & $0.001(0.065)$ & \\
\hline Total equated credits & $1.034(0.718)$ & $0.966(0.732)$ & & $0.865(0.902)$ & & $1.032(0.775)$ & \\
\hline College level credits & $0.058(0.635)$ & $0.046(0.645)$ & & $0.007(0.796)$ & & $-0.029(0.683)$ & \\
\hline Took college exit exam & $0.003(0.009)$ & $0.004(0.009)$ & & $0.003(0.012)$ & & $0.005(0.010)$ & \\
\hline Passed college exit exam & $0.001(0.009)$ & $0.002(0.009)$ & & $0.005(0.011)$ & & $0.005(0.010)$ & \\
\hline Score on college exit exam* & $-0.085(0.443)$ & $-0.051(0.446)$ & & $0.615(0.559)$ & & $0.312(0.491)$ & \\
\hline Bandwidth & $+/-6$ points & +/- 6 points & & +/- 4 points & & +/- 12 points & \\
\hline Functional form & Local linear & Local linear & & Local linear & & Local quadratic & \\
\hline School/cohort FE & $X$ & $x$ & & $x$ & & $X$ & \\
\hline Covariates & $X$ & & & $X$ & & $X$ & \\
\hline Sample size & 25,970 & 25,970 & & 17,641 & & 49,204 & \\
\hline
\end{tabular}

Source: Restricted use database covering placement test takers at LUCCS community colleges.

Notes: All outcomes measured three years after test date unless otherwise noted. Outcomes for college-level math include zeros for those who never took college-level math. Equated credits are a measure of total credits which include remedial coursework. Estimates of effects on exit exam scores are not strictly causal because they are computed only for those students (representing approximately 17 percent of the analysis sample) who took the exam; however, because there is no impact on taking the exam, this limits the concern that such comparisons are biased by differential selection. 
Table 3. Impacts of Reading+Writing Remedial Assignment Versus Writing-Only Assignment

\begin{tabular}{|c|c|c|c|c|c|c|c|c|}
\hline Outcome & \multicolumn{2}{|c|}{$\begin{array}{l}\text { Main Specification } \\
\text { B } \quad(\text { SE) }\end{array}$} & \multicolumn{2}{|c|}{ No Covariates } & \multicolumn{2}{|c|}{$\begin{array}{l}\text { Narrow Bandwidth } \\
\begin{array}{cc}\mathrm{B} & (\mathrm{SE})\end{array} \\
\end{array}$} & \multicolumn{2}{|c|}{$\begin{array}{l}\text { Wide Bandwidth } \\
\text { B } \quad(\mathrm{SE})\end{array}$} \\
\hline Enrolled immediately & 0.032 & $(0.016)$ * & 0.032 & $(0.017)$ * & 0.035 & $(0.021)$ * & 0.013 & $(0.018)$ \\
\hline Enrolled w/in 3 years & 0.010 & $(0.014)$ & 0.009 & $(0.015)$ & 0.018 & $(0.018)$ & 0.005 & $(0.016)$ \\
\hline Took dev writing & 0.085 & $(0.017)^{* * *}$ & 0.083 & $(0.017) * * *$ & 0.109 & $(0.022) * * *$ & 0.080 & $(0.019) * * *$ \\
\hline Took dev reading & 0.478 & $(0.015)^{* \star \star}$ & 0.478 & $(0.015)^{* \star *}$ & 0.504 & $(0.019) * * *$ & 0.451 & $(0.016) * \star \star *$ \\
\hline Took college-level English & -0.006 & $(0.019)$ & -0.006 & $(0.020)$ & 0.021 & $(0.025)$ & -0.016 & $(0.021)$ \\
\hline Passed college-level English & -0.006 & $(0.019)$ & -0.007 & $(0.019)$ & 0.012 & $(0.024)$ & -0.011 & $(0.021)$ \\
\hline Earned $\mathrm{C}$ or higher in CL English & 0.001 & $(0.019)$ & 0.000 & $(0.019)$ & 0.015 & $(0.024)$ & -0.003 & $(0.021)$ \\
\hline Earned B or higher in CL English & -0.008 & $(0.017)$ & -0.009 & $(0.017)$ & 0.005 & $(0.021)$ & -0.006 & $(0.018)$ \\
\hline Earned $A A$ & -0.005 & $(0.011)$ & -0.006 & $(0.011)$ & -0.016 & $(0.013)$ & -0.005 & $(0.011)$ \\
\hline Earned AA or transferred w/in 3 & -0.008 & $(0.012)$ & -0.010 & $(0.012)$ & -0.024 & $(0.015)$ & -0.006 & $(0.013)$ \\
\hline Still persisting & 0.002 & $(0.017)$ & 0.002 & $(0.017)$ & 0.042 & $(0.022) *$ & 0.014 & $(0.019)$ \\
\hline Dropped out & 0.008 & $(0.019)$ & 0.010 & $(0.019)$ & -0.017 & $(0.024)$ & -0.006 & $(0.020)$ \\
\hline Semesters enrolled & 0.061 & $(0.096)$ & 0.047 & $(0.099)$ & 0.134 & $(0.122)$ & 0.082 & $(0.105)$ \\
\hline Total equated credits & 1.711 & $(1.110)$ & 1.446 & $(1.148)$ & 2.489 & $(1.408)$ * & 2.220 & $(1.209)$ * \\
\hline College level credits & -0.052 & $(0.939)$ & -0.270 & $(0.970)$ & 0.197 & $(1.191)$ & 0.470 & $(1.018)$ \\
\hline Took college exit exam & 0.001 & $(0.013)$ & -0.001 & $(0.013)$ & 0.001 & $(0.017)$ & 0.004 & $(0.014)$ \\
\hline Passed college exit exam & 0.003 & $(0.013)$ & 0.002 & $(0.013)$ & 0.003 & $(0.016)$ & 0.008 & $(0.014)$ \\
\hline Score on college exit exam* & 0.289 & $(0.865)$ & 0.103 & $(0.871)$ & 0.724 & $(1.129)$ & 1.136 & $(0.943)$ \\
\hline Bandwidth & \multicolumn{2}{|c|}{$+/-6$ points } & \multicolumn{2}{|c|}{$+/-6$ points } & \multicolumn{2}{|c|}{$+/-4$ points } & \multicolumn{2}{|c|}{$+/-12$ points } \\
\hline Functional Form & \multicolumn{2}{|c|}{ Local Linear } & \multicolumn{2}{|c|}{ Local Linear } & \multicolumn{2}{|c|}{ Local Linear } & \multicolumn{2}{|c|}{ Local Quadratic } \\
\hline School/Cohort FE & \multicolumn{2}{|c|}{$\mathrm{x}$} & \multicolumn{2}{|r|}{$x$} & \multicolumn{2}{|r|}{$X$} & \multicolumn{2}{|r|}{$X$} \\
\hline Covariates & \multicolumn{2}{|r|}{$\mathrm{X}$} & & \multicolumn{2}{|r|}{$\mathrm{X}$} & \multicolumn{2}{|r|}{$x$} \\
\hline Sample size & \multicolumn{2}{|c|}{10663} & \multicolumn{2}{|c|}{10663} & \multicolumn{2}{|c|}{7049} & \multicolumn{2}{|c|}{20683} \\
\hline
\end{tabular}

Source: Restricted use database covering placement test takers at LUCCS community colleges.

Notes: All outcomes measured three years after test date unless otherwise noted. Outcomes for college-level math include zeros for those who never took college-level math. Equated credits are a measure of total credits which include remedial coursework. Estimates of effects on exit exam scores are not strictly causal because they are computed only for those students (representing approximately 17 percent of the analysis sample) who took the exam; however, because there is no impact on taking the exam, this limits the concern that such comparisons are biased by differential selection. 
Table 4. Impacts of Reading Remedial Assignment Versus College-Level Placement

\begin{tabular}{|c|c|c|c|c|c|c|c|c|}
\hline \multirow[b]{2}{*}{ Outcome } & \multicolumn{2}{|c|}{ Main Specification } & \multicolumn{2}{|c|}{ No Covariates } & \multicolumn{2}{|c|}{ Narrow Bandwidth } & \multicolumn{2}{|c|}{ Wide Bandwidth } \\
\hline & $\mathrm{B}$ & (SE) & $\mathrm{B}$ & (SE) & $\mathrm{B}$ & (SE) & B & (SE) \\
\hline Enrolled immediately & -0.027 & $(0.037)$ & -0.030 & $(0.037)$ & -0.025 & $(0.046)$ & -0.024 & $(0.040)$ \\
\hline Enrolled $w /$ in 3 years & -0.036 & $(0.033)$ & -0.044 & $(0.033)$ & -0.075 & $(0.041) *$ & -0.042 & $(0.036)$ \\
\hline Took dev writing & 0.007 & $(0.011)$ & 0.007 & $(0.011)$ & 0.000 & $(0.015)$ & 0.017 & $(0.012)$ \\
\hline Took dev reading & 0.559 & $(0.035) * * *$ & 0.552 & $(0.035) * * *$ & 0.573 & $(0.045)^{* * *}$ & 0.546 & $(0.040)^{* * *}$ \\
\hline Took college-level English & -0.155 & $(0.040) * * *$ & -0.160 & $(0.040) * * *$ & -0.184 & $(0.050) * * *$ & -0.145 & $(0.044) * * *$ \\
\hline Passed college-level English & -0.125 & $(0.043)^{* * *}$ & -0.134 & $(0.043) * * *$ & -0.143 & $(0.055)^{* * *}$ & -0.107 & $(0.047) * *$ \\
\hline Earned $\mathrm{C}$ or higher in CL English & -0.138 & $(0.044) * * *$ & -0.147 & $(0.044) * * *$ & -0.150 & $(0.055)^{* * *}$ & -0.135 & $(0.048) * * *$ \\
\hline Earned B or higher in CL English & -0.109 & $(0.044) * *$ & -0.113 & $(0.044) * *$ & -0.127 & $(0.055) * *$ & -0.097 & $(0.047) * *$ \\
\hline Earned $A A$ & -0.054 & $(0.031) *$ & -0.058 & $(0.032) *$ & -0.029 & $(0.039)$ & -0.050 & $(0.034)$ \\
\hline Earned AA or transferred w/in 3 & -0.047 & $(0.035)$ & -0.054 & $(0.035)$ & -0.022 & $(0.044)$ & -0.049 & $(0.038)$ \\
\hline Still persisting & -0.034 & $(0.036)$ & -0.038 & $(0.036)$ & -0.072 & $(0.045)$ & -0.037 & $(0.040)$ \\
\hline Dropped out & 0.080 & $(0.044)$ * & 0.091 & $(0.044) * *$ & 0.090 & $(0.055)$ & 0.083 & $(0.048)$ * \\
\hline Semesters enrolled & -0.236 & $(0.222)$ & -0.296 & $(0.224)$ & -0.225 & $(0.278)$ & -0.251 & $(0.241)$ \\
\hline Total equated credits & -2.306 & $(2.624)$ & -2.960 & (2.687) & -1.521 & (3.263) & -1.975 & $(2.850)$ \\
\hline College level credits & -4.228 & $(2.430) *$ & -4.837 & $(2.494)$ * & -3.183 & (3.023) & -4.058 & (2.633) \\
\hline Took college exit exam & -0.029 & $(0.037)$ & -0.036 & $(0.037)$ & 0.005 & $(0.047)$ & -0.020 & $(0.040)$ \\
\hline Passed college exit exam & -0.034 & $(0.036)$ & -0.040 & $(0.037)$ & -0.005 & $(0.046)$ & -0.024 & $(0.039)$ \\
\hline Score on college exit exam* & 1.352 & $(1.483)$ & 1.352 & $(1.511)$ & 2.090 & (1.937) & 1.553 & (1.585) \\
\hline Bandwidth & $+/-6$ & 6 points & $+/-6$ & points & $+/-$ & 4 points & $+/$ & 2 points \\
\hline Functional Form & Loca & al Linear & Loca & l Linear & Loce & al Linear & Local & Quadratic \\
\hline School/Cohort FE & & $x$ & & $x$ & & $x$ & & $x$ \\
\hline Covariates & & $x$ & & & & $x$ & & $x$ \\
\hline Sample size & & 2122 & & 122 & & 1374 & & 4381 \\
\hline
\end{tabular}

Source: Restricted use database covering placement test takers at LUCCS community colleges.

Notes: All outcomes measured three years after test date unless otherwise noted. Outcomes for college-level English include zeros for those who never took college-level English. Equated credits are a measure of total credits which include remedial coursework. Estimates of effects on exit exam scores are not strictly causal because they are computed only for those students (representing approximately 17 percent of the analysis sample) who took the exam; however, when there is no impact on taking the exam, this limits the concern that such comparisons are biased by differential selection. 
Table 5. Test Subgroup Results: Effects of Assignment to Math Remediation

\begin{tabular}{|c|c|c|c|}
\hline Outcome & $\begin{array}{c}\text { Full Sample } \\
\text { (Med. Bandwidth) }\end{array}$ & $\begin{array}{l}\text { Old Math Test } \\
\text { Subgroup }\end{array}$ & $\begin{array}{l}\text { New Math Test } \\
\text { Subgroup }\end{array}$ \\
\hline Enrolled immediately & $-0.020(0.010) * *$ & $-0.018(0.012)$ & $-0.023(0.021)$ \\
\hline Enrolled w/in 3 years & $-0.004(0.008)$ & $0.000(0.010)$ & $-0.011(0.018)$ \\
\hline Took dev math & $0.273(0.011)^{* * *}$ & $0.242(0.013) * * *$ & $0.400(0.022) * * *$ \\
\hline Took college-level math & $-0.077(0.012) * * *$ & $-0.066(0.014) * * *$ & $-0.119(0.025)$ *** \\
\hline Passed college-level math & $-0.050(0.012) * * *$ & $-0.038(0.013)^{* * *}$ & $-0.098(0.025) * * *$ \\
\hline Earned $\mathrm{C}$ or higher in $\mathrm{CL}$ math & $-0.043(0.011) * * *$ & $-0.035(0.013) * * *$ & $-0.077(0.024) * * *$ \\
\hline Earned $\mathrm{B}$ or higher in $\mathrm{CL}$ math & $-0.021(0.010) * *$ & $-0.016(0.011)$ & $-0.041(0.022) *$ \\
\hline Earned AA & $-0.002(0.008)$ & $0.003(0.009)$ & $-0.021(0.018)$ \\
\hline Earned AA or transferred & $-0.002(0.009)$ & $0.007(0.010)$ & $-0.031(0.020)$ \\
\hline Still persisting & $-0.008(0.011)$ & $-0.008(0.012)$ & $-0.008(0.021)$ \\
\hline Dropped out & $0.010(0.012)$ & $0.002(0.014)$ & $0.041(0.025)$ \\
\hline Semesters enrolled & $0.031(0.060)$ & $0.061(0.069)$ & $-0.079(0.122)$ \\
\hline Total equated credits & $1.034(0.718)$ & $1.520(0.818)$ * & $-0.855(1.501)$ \\
\hline College level credits & $0.058(0.635)$ & $0.696(0.716)$ & $-2.340(1.360)$ * \\
\hline Took college exit exam & $0.003(0.009)$ & $0.011(0.010)$ & $-0.024(0.020)$ \\
\hline Passed college exit exam & $0.001(0.009)$ & $0.007(0.010)$ & $-0.021(0.020)$ \\
\hline Score on college exit exam* & $-0.085(0.443)$ & $-0.336(0.522)$ & $0.514(0.844)$ \\
\hline Bandwidth & $+/-6$ points & +/- 6 points & $+/-6$ points \\
\hline Functional form & Local linear & Local linear & Local linear \\
\hline School/cohort FE & $X$ & $x$ & $x$ \\
\hline Covariates & $x$ & $x$ & $x$ \\
\hline Sample size & 25,970 & 19,613 & 6,357 \\
\hline
\end{tabular}

Source: Restricted use database covering placement test takers at LUCCS community colleges.

Notes: All outcomes measured three years after test date unless otherwise noted.

Approximately 76 percent of tested students enroll immediately and 84 percent enroll within 
Table 6. Risk Subgroup Results: Effects of Assignment to Math Remediation

\begin{tabular}{|c|c|c|c|c|c|c|c|}
\hline Outcome & $\begin{array}{c}\text { Full Sample } \\
\text { (Med. Bandwidth) }\end{array}$ & $\begin{array}{c}\text { Lower-Risk } \\
\text { Subgroup }\end{array}$ & & $\begin{array}{c}\text { Middle-Risk } \\
\text { Subgroup }\end{array}$ & & $\begin{array}{c}\text { Highest Risk } \\
\text { Subgroup }\end{array}$ & \\
\hline Enrolled immediately & $-0.020(0.010) * *$ & $-0.021(0.021)$ & & $-0.029(0.014)$ & ** & $-0.028(0.021)$ & \\
\hline Enrolled w/in 3 years & $-0.004(0.008)$ & $-0.008(0.017)$ & & $-0.013(0.012)$ & & $-0.003(0.019)$ & \\
\hline Took dev math & $0.273(0.011) * * *$ & $0.366(0.022)$ & $* \star *$ & $0.261(0.016)$ & $* \star *$ & $0.214(0.023)$ & *** \\
\hline Took college-level math & $-0.077(0.012) * * *$ & $-0.076(0.025)$ & $* * *$ & $-0.092(0.018)$ & $* * *$ & $-0.075(0.024)$ & *** \\
\hline Passed college-level math & $-0.050(0.012) * * *$ & $-0.089(0.025)$ & $* * *$ & $-0.054(0.018)$ & $* * *$ & $-0.033(0.022)$ & \\
\hline Earned $\mathrm{C}$ or higher in $\mathrm{CL}$ math & $-0.043(0.011) * * *$ & $-0.086(0.025)$ & *** & $-0.037(0.017)$ & $* *$ & $-0.032(0.021)$ & \\
\hline Earned B or higher in CL math & $-0.021(0.010) * *$ & $-0.043(0.024)$ & * & $-0.022(0.014)$ & & $-0.006(0.018)$ & \\
\hline Earned AA & $-0.002(0.008)$ & $0.010(0.020)$ & & $-0.009(0.011)$ & & $-0.006(0.013)$ & \\
\hline Earned AA or transferred & $-0.002(0.009)$ & $0.018(0.022)$ & & $-0.012(0.013)$ & & $-0.011(0.014)$ & \\
\hline Still persisting & $-0.008(0.011)$ & $0.012(0.023)$ & & $-0.024(0.016)$ & & $-0.008(0.021)$ & \\
\hline Dropped out & $0.010(0.012)$ & $-0.030(0.026)$ & & $0.037(0.018)$ & ** & $0.021(0.023)$ & \\
\hline Semesters enrolled & $0.031(0.060)$ & $0.099(0.124)$ & & $-0.110(0.086)$ & & $0.053(0.123)$ & \\
\hline Total equated credits & $1.034(0.718)$ & $1.289(1.557)$ & & $-0.373(1.030)$ & & $1.104(1.386)$ & \\
\hline College level credits & $0.058(0.635)$ & $0.337(1.404)$ & & $-1.295(0.906)$ & & $0.319(1.198)$ & \\
\hline Took college exit exam & $0.003(0.009)$ & $-0.004(0.023)$ & & $-0.003(0.013)$ & & $0.013(0.015)$ & \\
\hline Passed college exit exam & $0.001(0.009)$ & $-0.007(0.022)$ & & $-0.005(0.013)$ & & $0.009(0.015)$ & \\
\hline Score on college exit exam* & $-0.085(0.443)$ & $0.358(0.692)$ & & $-0.611(0.694)$ & & $-0.868(1.312)$ & \\
\hline Bandwidth & $+/-6$ points & $+/-6$ points & & $+/-6$ points & & $+/-6$ points & \\
\hline Functional form & Local linear & Local linear & & Local linear & & Local linear & \\
\hline School/cohort FE & $\mathrm{X}$ & $X$ & & $X$ & & $X$ & \\
\hline Covariates & $X$ & $X$ & & $\mathrm{X}$ & & $\mathrm{X}$ & \\
\hline Sample size & 25,970 & 6,141 & & 12,192 & & 6,282 & \\
\hline
\end{tabular}

Source: Restricted use database covering placement test takers at LUCCS community colleges.

Notes: All outcomes measured three years after test date unless otherwise noted. Approximately 76 percent of tested students enroll immediately and 84 percent enroll within three years. 